LA W RENCE LIVERMORE N A T IO N A L LABORATORY

\title{
Relativistic Double Group Spinor Representations of Non-rigid Molecules
}

K. Balasubramanian

December 29, 2003

Journal of Chemical Physics 
This document was prepared as an account of work sponsored by an agency of the United States Government. Neither the United States Government nor the University of California nor any of their employees, makes any warranty, express or implied, or assumes any legal liability or responsibility for the accuracy, completeness, or usefulness of any information, apparatus, product, or process disclosed, or represents that its use would not infringe privately owned rights. Reference herein to any specific commercial product, process, or service by trade name, trademark, manufacturer, or otherwise, does not necessarily constitute or imply its endorsement, recommendation, or favoring by the United States Government or the University of California. The views and opinions of authors expressed herein do not necessarily state or reflect those of the United States Government or the University of California, and shall not be used for advertising or product endorsement purposes. 


\title{
Relativistic Double Group Spinor Representations of Non-rigid Molecules
}

\author{
K. Balasubramanian* \\ Center for Image Processing and Integrated computing, University of \\ California Davis, Livermore, CA 94550; University of California \\ Chemistry and Material Science Directorate \\ Lawrence Livermore National Laboratory \\ Livermore, California 94550; \\ and Glenn T Seaborg Center, Lawrence Berkeley Laboratory, University \\ of California, Berkeley, CA 94720
}

The character theory of relativistic double group spinor representations is developed in order to represent the total rovibronic states of non-rigid molecules. It is shown that the double groups can be represented in terms of wreath products and powerful matrix cycle type generators that are used to construct their character tables. It is shown that these tables are of use when spin-orbit coupling is included in the hamiltonian even for molecules containing lighter atoms. Applications to non-rigid molecules such as $\mathrm{Tl}_{2} \mathrm{H}_{4}$ $/ \mathrm{Tl}_{2} \mathrm{H}_{4}{ }^{+}$are considered. It is shown that the tunneling splittings and the nuclear spin statistical weights can be obtained for such species using the character tables thus constructed. The spinor double groups of several other molecules such as hexamethyl dilead and heavy weakly bound clusters such as $\left(\mathrm{PoH}_{2}\right)_{4}$ are also considered.

\footnotetext{
*Address correspondence at kbala@ucdavis.edu or fax:925-422-6810
} 


\section{Introduction}

Relativistic spinor representations of molecules require a double group approach due to the incorporation of spin-orbit interaction term into the hamiltonian ${ }^{1-7}$. Many years ago, Longuet-Higgins ${ }^{8}$ formulated the symmetry groups of non-rigid molecules as permutation-inversion groups. Longuet-Higgins ${ }^{8}$ noted that the treatment of rovibronic levels of non-rigid molecules, which typically exhibit potential energy surfaces with surmountable energy barriers, requires a group-theoretical approach that includes all feasible permutations of the nuclei under fluxional motions. In conclusion LonguetHiggins ${ }^{8}$ noted that the inclusion of spin-orbit coupling for non-rigid molecules needs to be considered as a separate topic. Up to now it appears that this has not been considered systematically for heavy non-rigid species for which spin-orbit effects become important.

The double group theory of rigid point groups has been considered by a number of workers. In particular Pyykkö and coworkers ${ }^{2,4}$ have provided relativistic double group treatments in $\mathrm{D}_{3 \mathrm{~h}}$ and $\mathrm{T}_{\mathrm{h}}$ groups while the current author has considered the double group of the icosahedral group ${ }^{5}$. The present author ${ }^{9}$ has also considered the development of non-rigid molecular groups as wreath product groups and as generalized wreath products. The wreath product groups have also been used in a number of chemical applications ${ }^{10-16}$ such as enumeration of isomers, weakly-bound van der waals or hydrogen-bonded complexes $^{11,14,21-23}$, polyhedral structures ${ }^{18,19}$, spectroscopy ${ }^{11,16,17}$, and clusters. King ${ }^{18,19}$ has used the wreath product groups to represent the symmetries of four-dimensional analogues of polyhedra. Up to now many of these applications were restricted only for non-rigid species without consideration of spin-orbit coupling. Introduction of the spinorbit term into the hamiltonian results in an additional $\mathrm{R}$ operation, which leads to a sign change for a rotation by $360^{\circ}$. The new group that has twice the number of elements as the permutation-inversion group is not a direct product of the PI group and the group with $\mathrm{R}$ and identity operations. This is due to the fact that some conjugacy classes double by the introduction of $\mathrm{R}$, while the others do not ${ }^{3,7}$. Moreover, the character values for some conjugacy classes of the double group are irrational numbers. Consequently, the generation of the double group character tables of non-rigid molecules is far more challenging than the normal point group tables. 
Spin-orbit effects become very significant for molecules containing very heavy atoms $^{1-7}$, and even for systems with second and third row elements spin-orbit effects can be appreciable if one seeks to obtain results of spectroscopic accuracies. Species that have overall half-integral spin states cannot be treated correctly within the normal permutation-inversion groups or point groups. Molecules containing very heavy atoms such as $\mathrm{Tl}$ often exhibit weaker Tl-Tl bonding, and thus internal rotation around such bonds would have small and surmountable energy barriers. The barrier to internal rotation around the Tl-Tl bond is only 5-8 kcal/mole in $\mathrm{Tl}_{2} \mathrm{H}_{4}{ }^{27}$. Pyykkö and coworkers ${ }^{24}$ have shown that intermolecular dimerization energies for species such as $\left(\mathrm{H}_{2} \mathrm{E}-\mathrm{EH}_{2}\right)_{2}$, $(\mathrm{HE}-\mathrm{EH})_{2}$ for $\mathrm{E}=\mathrm{As}$ to Po are only 8 to $13 \mathrm{~kJ} / \mathrm{mole}$ suggesting the non-rigid nature of these species. In fact $\mathrm{PoH}_{2}$ exists as a liquid in its most stable form. Likewise hexamethyl dilead $^{25}$ would have a low surmountable barrier to rotation around the $\mathrm{Pb}-\mathrm{Pb}$ bond due to rather weak bonding between $\mathrm{Pb}$ atoms caused by spin-orbit destabilization. The rovibronic levels of such species have to be considered as direct products of rotational, vibrational and electronic levels as classified in the double group of the non-rigid molecule. The rotational levels are well known to exhibit tunneling splittings due to nonrigid motions. This would in turn be reflected as split rovibronic levels in the double group. Consequently, the correct treatment of the spectroscopic properties of such molecules exhibiting both spin-orbit coupling and non-rigid motions must be considered in the double group of the non-rigid permutation-inversion groups.

In the current work, we provide a systematic approach to the character tables of the double groups of non-rigid molecules. We use the matrix-cycle-type generators for the construction of the character tables. The method provides both the conjugacy classes and the character values of the double groups of wreath product groups. It is shown that the rovibronic levels and nuclear spin statistical weights of such species can be obtained from the double group character tables. We illustrate our techniques with a number of examples to show that these groups can be expressed as double groups of wreath products of permutation groups $\mathrm{S}_{\mathrm{n}}{ }^{24}$ We have provided 3 complete illustrative examples of double groups, $\left\{\mathrm{S}_{2}\left[\mathrm{~S}_{2}\right]\right\}^{2},\left\{\mathrm{~S}_{2}\left[\mathrm{~S}_{3}\right]\right\}^{2}$ and $\left\{\mathrm{S}_{4}\left[\mathrm{~S}_{2}\right]\right\}^{2}$. There could be higher order double wreath product groups for larger weakly-bound clusters, and the current technique can be extended to apply to those systems as spectroscopic data become available. 


\section{Wreath Product Double Group Approach to Non-rigid Molecules}

The motivation for the development of double groups of non-rigid molecules containing very heavy atoms stems from the computations of species such as $\mathrm{Tl}_{2} \mathrm{H}_{4}{ }^{27}$. Molecules containing such very heavy metal-metal bonds exhibit surmountable barriers to rotation around the metal-metal bonds due to the weaker dimer bonds of sixth row elements as a consequence of the relativistic inert pair effect. In the case of $\mathrm{Tl}, \mathrm{Pb}, \mathrm{Bi}, \mathrm{Po}$, etc. the bonding between themselves is weakened by large spin-orbit coupling. In fact, the $\mathrm{Pb}-\mathrm{Pb}$ bond energy is wakened by a factor of 2 by spin-orbit coupling due to the mixing of the antibonding orbitals with bonding orbitals in the spinor representations. Our computed barrier for the internal rotation around the Tl-Tl bond to convert the twisted structure into the planar structure is $7 \mathrm{kcal} / \mathrm{mole}$ at the MP2 level and 7.9 $\mathrm{kcal} / \mathrm{mole}$ at the CCSD (T) level ${ }^{27}$. The spin-orbit coupling. weakens the Tl-Tl bond substantially and thus we expect the barrier to reduce by less than $4 \mathrm{kcal} / \mathrm{mole}$ in the presence of spin-orbit effects ${ }^{27}$.

$\mathrm{The} \mathrm{Pb}-\mathrm{Pb}$ internal rotation should also have a small barrier. This appears to be the case for the reported structure of hexamtethyl di-lead ${ }^{25}$. Other cases that would involve molecules containing heavy atoms with surmountable barriers are clusters of $\mathrm{PoH}_{2}$, which are weakly bound. For even molecules containing lighter elements such as $\mathrm{Si}, \mathrm{As}, \mathrm{P}$, etc., the spin-orbit effects need to be considered if spectroscopic accuracy is desired. In those cases, we need to consider double groups of the non-rigid molecular groups should the molecule exhibit a potential energy surface with surmountable energy barriers. It is thus evident that the gap in the literature for the character theory of double groups of non-rigid molecular frameworks needs to be filled.

The ordinary symmetry group of a non-rigid molecule can be expressed as permutations and inversion operations of the nuclei in the molecular framework ${ }^{8}$. Let $\mathrm{G}$, be a set of permutations(and in general permutation-inversion operations) of the rigid part of a molecule. In some cases $\mathrm{G}$ may become isomorphic to the complete set of $\mathrm{n}$ ! permutations of $\mathrm{n}$ objects, in which case, it is denoted by the permutation group $\mathrm{S}_{\mathrm{n}}$. In general the $S_{n}$ group ${ }^{26}$ consists of $n$ ! permutations of $n$ objects in a set $\Omega$ of chosen nuclei in the molecule to represent the rigid framework. As an example we may consider the 
$\mathrm{Tl}_{2} \mathrm{H}_{4}$ molecule. The rigid part of the molecule consists only of the $\mathrm{Tl}$ atoms and thus the permutations of the $\mathrm{Tl}$ nuclei span a permutation group of 2 permutations isomorphic to the $\mathrm{S}_{2}$ permutation group. The internal rotation around the $\mathrm{T}-\mathrm{Tl}$ bond switches the hydrogen atoms attached to each of the $\mathrm{Tl}$ atom. Let the permutations of each pair of hydrogen atoms be the group $\mathrm{H}$, which in this case, is also isomorphic to the $\mathrm{S}_{2}$ group of permutations of the hydrogens on each $\mathrm{Tl}$ atom. The overall group of $\mathrm{Tl}_{2} \mathrm{H}_{2}$ then becomes the wreath product of $\mathrm{G}$ with $\mathrm{H}$, denoted by $\mathrm{G}[\mathrm{H}]$. In this case, the permutation group of the non-rigid $\mathrm{Tl}_{2} \mathrm{H}_{2}$ molecule is the wreath product group, $\mathrm{S}_{2}\left[\mathrm{~S}_{2}\right]$ since both $\mathrm{G}$ and $\mathrm{H}$ are $\mathrm{S}_{2}$ groups. In general, the wreath product group $\mathrm{G}[\mathrm{H}]$ consists of permutations

$$
\{(\mathrm{g} ; \pi) \mid \pi \text { mapping of } \Omega \text { into } \mathrm{H}, \mathrm{g} \varepsilon \mathrm{G}\}
$$

such that the product of two permutations is defined as

$$
(\mathrm{g} ; \pi)\left(\mathrm{g} ; \pi^{\prime}\right)=\left(\mathrm{gg}^{\prime} ; \pi \pi_{\mathrm{g}}{ }^{\prime}\right)
$$

where

$$
\begin{gathered}
\pi_{\mathrm{g}}(\mathrm{i})=\pi\left(\mathrm{g}^{-1} \mathrm{i}\right), \forall \mathrm{i} \varepsilon \Omega, \\
\pi \pi^{\prime}(\mathrm{i})=\pi(\mathrm{i}) \pi^{\prime}(\mathrm{i}), \forall \mathrm{i} \varepsilon \Omega .
\end{gathered}
$$

A given element of $G[H]$ is represented by $\left(g ; h_{1}, h_{2}, \ldots . . h_{n}\right)$, where $g \varepsilon G$ and $h_{i} \varepsilon H$. Thus the group $\mathrm{G}[\mathrm{H}]$ contains $|\mathrm{G} \| \mathrm{H}|^{\mathrm{n}}$ elements where $\mathrm{n}$ is the order of $\Omega$. For $\mathrm{Tl}_{2} \mathrm{H}_{4}$ the order of the non-rigid permutation group is

$$
\left|\mathrm{S}_{2}\left[\mathrm{~S}_{2}\right]\right|=2 !(2 !)^{2}=8 \text {. }
$$

It can be seen that the group $\mathrm{G}[\mathrm{H}]$ is isomorphic with

$$
G[H]=\left(H_{1} \times H_{2} \times \ldots H_{n}\right) \wedge G^{\prime},
$$

where $\mathrm{H}_{1}, \mathrm{H}_{2}, \ldots \mathrm{H}_{\mathrm{n}}$ are all isomorphic copies of the same group $\mathrm{H}$, $\mathrm{x}$ symbol stands for direct product while ${ }^{\wedge}$ symbol represents a semi-direct product. The group $\mathrm{H}_{1} \times \mathrm{H}_{2} \times \ldots \mathrm{H}_{n}$ is an invariant subgroup of $\mathrm{G}[\mathrm{H}]$, which is why the product outside parenthesis is a semidirect product.

The character theory of the wreath product groups and the generalized wreath product groups are quite well developed ${ }^{10,12,15}$. The current author ${ }^{10}$ has developed generating function algorithms for the character values of the various irreducible 
representations of wreath product groups. Before we start the double group formalism, the character generating method of wreath products is briefly outlined. The conjugacy classes of wreath product $S_{n}[H]$ groups are characterized by matrix types obtained from the permutation cycle type or orbit structure of $g$ and the conjugacy class information of $H$. Let a permutation $g \varepsilon G$ give rise to $a_{1}$ cycles of length 1 , $a_{2}$ cycles of length $2, \ldots . . a_{n}$ cycles of length $\mathrm{n}$ upon its action on the set $\Omega$. The cycle type of $\mathrm{G}$ is then denoted by $\mathrm{T}_{\mathrm{g}}=\left(\mathrm{a}_{1}, \mathrm{a}_{2}, \ldots . \mathrm{a}_{\mathrm{n}}\right)$. To illustrate a permutation (12) of the $\mathrm{Tl}$ nuclei would have the cycle type $(0,1)$. If we denote the conjugacy classes of $H$ by $C_{1}, C_{2}, \ldots C_{s}$, and since $G$ is a complete $S_{n}$ group of $n$ ! permutations, we can express the cycle type of an element in the wreath product $\mathrm{G}[\mathrm{H}]$ by a sxn matrix, $\mathrm{T}(\mathrm{g} ; \pi)$ also known as the cycle type of $(\mathrm{g} ; \pi)$. Let $a_{i k}$ of the cycle products of $G$ belong to the conjugacy class $C_{i}$, we thus define the cycle type of $(g ; \pi)$, which represents the conjugacy class of $S_{n}[H]$ as

\section{$T(g ; \pi)=a_{i k}(1 \leq i \geq s, 1 \leq k \geq n)$.}

Table I shows the cycle matrix types for the conjugacy classes of the non-group of $\mathrm{Tl}_{2} \mathrm{H}_{4}$ or the $\mathrm{S}_{2}\left[\mathrm{~S}_{2}\right]$ group. We construct these matrices first by getting the two cycle types of the elements in $\mathrm{G},(2,0),(0,1)$ and then using the above algorithm. Let $\mathrm{P}(\mathrm{m})$ denote the number of partitions of integer $m$ with the convention that $P(0)=1$. Let $n$ be partitioned into ordered s-tuples, where $s$ is the no of conjugacy classes of $H,(n)=\left(n_{1}, n_{2}, \ldots . n_{s}\right)$ such that $\sum_{i} n_{i}=n$. Then the number of conjugacy classes of $\mathrm{S}_{\mathrm{n}}[\mathrm{H}]$ is given by

$$
\sum_{n} P\left(n_{1}\right) P\left(n_{2}\right) \ldots P\left(n_{s}\right)
$$

As an illustration for $\mathrm{Tl}_{2} \mathrm{H}_{4}$, the $\mathrm{S}_{2}\left[\mathrm{~S}_{2}\right]$ group has the ordered partitions $(2,0),(0,2),(1,1)$, since the $S_{2}$ group has 2 conjugacy classes. Substituting the values of $P(2)=2, P(1)=1$ and $\mathrm{P}(0)=1$ in the above expression we obtain the number of conjugacy classes of $\mathrm{S}_{2}\left[\mathrm{~S}_{2}\right]$ as $2+2+1=5$. Five conjugacy classes thus obtained are shown in Table I. The number of elements in each conjugacy class of $\mathrm{S}_{\mathrm{n}}[\mathrm{H}]$ is given by 


$$
\frac{\left|S_{n}[H]\right|}{\prod_{i, k} a_{i k} !\left(k|H| \mid C_{i}\right)^{a_{k}}}
$$

To illustrate consider the the number of elements in the third conjugacy class with the matrix type $\left[\begin{array}{ll}1 & 0 \\ 1 & 0\end{array}\right]$ is given by

$$
\frac{2 ! \cdot(2 !)^{2}}{1 !(1.2 / 1)^{1} 1 !(1.2)^{1}}=2
$$

All conjugacy classes thus obtained with the number of elements in each class are shown in Table I. It is interesting to note that the $S_{2}\left[S_{2}\right]$ group is isomorphic with the $D_{4}$ point group of 8 elements. The complete PI group is obtained as the direct product of $\mathrm{S}_{2}\left[\mathrm{~S}_{2}\right]$ and the I group, which has the identity and inversion operations.

The character tables of the $S_{n}[H]$ groups can be obtained with combinatorial generating functions that employ matrix type polynomials. All possible irreducible representations of the $S_{n}[H]$ group are constructed using induced representations from a smaller group to a larger group 9 . It is well known that the irreducible representations of the $S_{n}$ group $^{26}$ are represented by the partitions of $n$, denoted by $\left[n_{1} n_{2} \ldots n_{m}\right]$, where $n_{1}$, $\mathrm{n}_{2} \ldots \mathrm{n}_{\mathrm{m}}$ is a partition of the integer $\mathrm{n}$. Thus the irreducible representations of the $\mathrm{S}_{2}$ group are [2] and $\left[1^{2}\right]$. The irreducible representations of $S_{n}[H]$ are constructed by first forming the outer tensor (outer direct) products of the irreducible representations of $\mathrm{H} \mathrm{n}$ times, then finding the inertia factor of each such product, and subsequently inducing the representation from the inertia factor group to the whole group. For example, the unique outer products for the irreducible representations of $S_{2} \times S_{2}$ are given by

$$
[2] \#[2], \quad[2] \#\left[1^{2}\right] \text {, and }\left[1^{2}\right] \#\left[1^{2}\right] \text {. }
$$

The inertia factor groups (subgroup of $\mathrm{G}$ ) of the above products are $\mathrm{S}_{2}{ }^{\prime}, \mathrm{S}_{1}{ }^{\prime}$ (identity group), and $\mathrm{S}_{2}{ }^{\prime}$ respectively. The overall representations of the $\mathrm{S}_{\mathrm{n}}[\mathrm{H}]$ groups are obtained 
by multiplying the unique outer products of irreducible representations of $\mathrm{H}$ with the irreducible representations of the factor group G' for each product, and then inducing the whole representation into $\mathrm{G}[\mathrm{H}]$. That is, the irreducible representations of $\mathrm{G}[\mathrm{H}]$ are given by

$$
F^{*}=\left(F_{1} \# F_{2} \# \ldots . . . F_{n}\right) \otimes F^{\prime} \uparrow G[H],
$$

where $F_{1} \# F_{2} \# \ldots . . F_{n}$ is the outer tensor product of the irreducible representations $\left(\mathrm{F}_{1}, \mathrm{~F}_{2} \ldots \mathrm{F}_{\mathrm{n}}\right)$ from the Group $\mathrm{H}$, \# is the outer product, $\mathrm{F}^{\prime}$ is an irreducible representation of the factor group G', $\otimes$ represents an inner product, and the $\uparrow$ stands for an induced representation to the whole group $\mathrm{G}[\mathrm{H}]$.

The above technique of enumerating the irreducible representations of the $S_{2}\left[S_{2}\right]$ group can be illustrated for the $\mathrm{Tl}_{2} \mathrm{H}_{4}$ molecule. The five representations of the $\mathrm{S}_{2}\left[\mathrm{~S}_{2}\right]$ group are given by

$$
\begin{aligned}
& \mathrm{A}_{1}=([2] \#[2] \#) \otimes[2]^{\prime}, \mathrm{A}_{2}=([2] \#[2]) \otimes\left[1^{2}\right]^{\prime}, \\
& \mathrm{E}=\left([2] \#\left[1^{2}\right]\right) \otimes[1]^{\prime} \uparrow \mathrm{S}_{2}\left[\mathrm{~S}_{2}\right], \mathrm{B}_{1}=\left(\left[1^{2}\right] \#\left[1^{2}\right]\right) \otimes[2] ' \uparrow \mathrm{S}_{2}\left[\mathrm{~S}_{2}\right], \\
& \mathrm{B}_{2}=\left(\left[1^{2}\right] \#\left[1^{2}\right]\right) \otimes\left[1^{2}\right]^{\prime},
\end{aligned}
$$

The whole permutation-inversion group can be obtained as the direct product of $S_{2}\left[S_{2}\right]$ with the I group since the inversion operation does not generate any new permutation, it is denoted by $\mathrm{E}^{*}$.

The character tables of the $\mathrm{S}_{\mathrm{n}}[\mathrm{H}]$ groups can be generated using the generating functions as polynomials of matrix cycle types. Balasubramanian ${ }^{10}$ has developed a general algorithm for the characters of the wreath product groups. In this method suppose $\mathrm{P}_{\mathrm{G}}{ }^{\chi}$ is the generalized character cycle index polynomial of the irreducible representation $\chi$ of the factor subgroup G' of G, and it is given by

$$
P_{G}^{\chi}=\frac{1}{|G|} \sum_{g \in G} \chi(g) s_{1}^{b_{1}} s_{2}^{b_{2}} \ldots \ldots . s_{n}^{b n}
$$

Let $\mathrm{T}(\mathrm{M})_{\mathrm{i}}$ be the matrix type of the representation of the inertia factor. The generating function for the irreducible representation $\mathrm{F}^{*}$ of $\mathrm{S}_{\mathrm{n}}[\mathrm{H}]$ is obtained by the following replacement: 


$$
T(G[H])^{F^{*}}=P_{G}^{\chi}\left(s_{i} \rightarrow T(M)_{i}\right)
$$

That is, in the above expression every $\mathrm{s}_{\mathrm{i}}$ is replaced by the correpsonding matrix type $\mathrm{T}(\mathrm{M})_{\mathrm{i}}$, where all algebraic manuiputalions are done with the cycle type matrices. We intriduce $\oplus, \otimes,-$ opertaions for additions, multiplications and subtractions to contrat that these are not ordinary matrix multiplications, etc. To illustrate, consider the $\mathrm{Tl}_{2} \mathrm{H}_{4}$ case.

$$
\begin{aligned}
& {\left[\begin{array}{ll}
1 & 0 \\
0 & 0
\end{array}\right]^{2}=\left[\begin{array}{ll}
2 & 0 \\
0 & 0
\end{array}\right]} \\
& {\left[\begin{array}{ll}
1 & 0 \\
0 & 0
\end{array}\right]\left[\begin{array}{ll}
0 & 0 \\
1 & 0
\end{array}\right]=\left[\begin{array}{ll}
1 & 0 \\
1 & 0
\end{array}\right]}
\end{aligned}
$$

Since this procedure involves several steps, let us consider a few examples. The $\mathrm{B}_{2}$ irerducible representaion given by $([2] \#[2]) \otimes\left[1^{2}\right]^{\prime}$. The generalized character cycle index of $\left[1^{2}\right]^{\prime}$, the factor group irreducibe representation, is given by

$$
P_{S_{2}}^{\left[1^{2}\right]}=\frac{1}{6}\left[s_{1}^{2}-s_{2}\right]
$$

For the representation [2], the matrix type expressions $\mathrm{T}(\mathrm{M})_{\mathrm{i}}$ are given as follows:

$$
\begin{aligned}
& T(M)_{1}{ }^{[2]}=\frac{1}{2}\left[\left[\begin{array}{ll}
1 & 0 \\
0 & 0
\end{array}\right] \oplus\left[\begin{array}{ll}
0 & 0 \\
1 & 0
\end{array}\right]\right] \\
& T(M)_{2}{ }^{[2]}=\frac{1}{2}\left[\left[\begin{array}{ll}
0 & 1 \\
0 & 0
\end{array}\right] \oplus\left[\begin{array}{ll}
0 & 0 \\
0 & 1
\end{array}\right]\right]
\end{aligned}
$$

Replacing every si by $\mathrm{T}(\mathrm{M}))_{\mathrm{i}}$ in the expression for $P_{S_{2}}^{\left[1^{3}\right]}$ we obtain

$$
G F_{B_{2}}=\frac{1}{2}\left[\frac{1}{2^{2}}\left\{\left[\begin{array}{ll}
1 & 0 \\
0 & 0
\end{array}\right] \oplus\left[\begin{array}{ll}
0 & 0 \\
1 & 0
\end{array}\right]\right\}^{2}-\frac{1}{2^{1}}\left\{\left[\begin{array}{ll}
0 & 1 \\
0 & 0
\end{array}\right] \oplus\left[\begin{array}{ll}
0 & 0 \\
0 & 1
\end{array}\right]\right\}\right]
$$


Using the matrix manipulations indicated above for the cycle types, we can simplify the above expression into

$$
G F_{B_{2}}=\frac{1}{2} \frac{1}{2^{2}}\left[\left[\begin{array}{ll}
2 & 0 \\
0 & 0
\end{array}\right]+2\left[\begin{array}{ll}
1 & 0 \\
1 & 0
\end{array}\right]+\left[\begin{array}{ll}
0 & 0 \\
2 & 0
\end{array}\right]-2\left[\begin{array}{ll}
0 & 1 \\
0 & 0
\end{array}\right]-2\left[\begin{array}{ll}
0 & 0 \\
0 & 1
\end{array}\right]\right]
$$

The above expression is a generating function for the character values with the order of the group (8) factored out. That is, the string of coefficients $\{1,2,1,-2,-2\}$ in the above expression gives the product of the character value and the number of elements in each conjugacy class. Thus the expression generates the character values $\{1,1,1,-1,-1\}$ when the number of elements in each conjugacy class is factored out. This corresponds to the character values of the $\mathrm{B}_{2}$ representation. Let us consider an induced representation, that is, the $E=\left(\left[1^{2}\right] \#[2]\right) \otimes[1]^{\prime} \uparrow S_{2}\left[S_{2}\right]$ irreducible representation of the $S_{2}\left[S_{2}\right]$ group. The expression for the character generating function is shown below:

$$
\begin{aligned}
& G F_{E}=\frac{1}{2}\left[\frac{1}{2}\left\{\left[\begin{array}{ll}
1 & 0 \\
0 & 0
\end{array}\right]-\left[\begin{array}{ll}
0 & 0 \\
1 & 0
\end{array}\right]\right\}\right] \\
& \times\left[\left\{\left[\begin{array}{ll}
1 & 0 \\
0 & 0
\end{array}\right] \oplus\left[\begin{array}{ll}
0 & 0 \\
1 & 0
\end{array}\right]\right\}\right]
\end{aligned}
$$

The above expression upon simplification yields

$$
G F_{E}=\frac{1}{2} \frac{1}{2^{2}}\left[2\left[\begin{array}{ll}
2 & 0 \\
0 & 0
\end{array}\right]-2\left[\begin{array}{ll}
2 & 0 \\
0 & 0
\end{array}\right]\right]
$$

From the above expression we obtain the string $\{2,-2,0,0,0\}$ from which the character for $\mathrm{E}$ is generated.

Next we go to the double group of the wreath products. The introduction of the spin-orbit coupling into the hamiltonian results in a symmetry analogous to the symmetry of a "Mobius surface", and thus rotation by $360^{\circ}$ results in a sign change. This is usually characterized by an operation $\mathrm{R}$ that is added to the PI group. This doubles the number of elements in the double group. However, the result of including the R operation into the PI 
group does not result in a direct product since some of the conjugacy classes double in their order, while other conjugacy classes result in new conjugacy classes upon multiplication by R. Consequently the first step to constructing the character table of the double groups of wreath products is to construct the conjugacy class structures after the introduction of the R operation.

If the double operation $\mathrm{R}$ (rotation by $360^{\circ}$ ) when multiplied by the permutation operation generates an equivalent operation to the permutation then both $\mathrm{P}$ and RP belong to the same conjugacy class. This can be determined by visualizing the permutation operation as a proper or improper rotation. For example, routinely pure $\mathrm{C}_{2}$ types of operations are two-sided axes in that the $\mathrm{C}_{2}$ and $\mathrm{C}_{2} \mathrm{R}$ become equivalent since $\mathrm{C}_{2}$ often changes its direction by application of another operation. Thus the $\mathrm{C}_{2}$ operation and $\mathrm{C}_{2} \mathrm{R}$ belong to the same conjugacy class. On the other hand, all other pure higher-order $C_{n}$ rotational axes lead to new conjugacy classes as $C_{n}$ and $C_{n} R$ are not equivalent. This is because $C_{n}$ and $C_{n}^{(n-1)}$ do not belong to the same conjugacy class in the double group as

$$
\mathrm{C}_{\mathrm{n}} \mathrm{C}_{\mathrm{n}}^{(\mathrm{n}-1)}=\mathrm{R}
$$

Thus for $n>2, C_{n}$ and $C_{n}^{(n-1)}$ belong to different conjugacy classes in the double group. We simply identify this as $\mathrm{C}_{\mathrm{n}} \mathrm{R}$ as a new conjugacy class. Once all proper rotations have thus been completed we would be left with only composite operations or improper rotations. Once these are expressed as products of the corresponding proper rotation and planes (inversions), we can identify if the operation will generate a new conjugacy class upon multiplication with $\mathrm{R}$ or not.

The above technique of generating conjugacy classes of the double groups is demonstrated for the wreath product $\mathrm{S}_{2}\left[\mathrm{~S}_{2}\right]$ in table 1 . As can be seen there, the identity operation will always generate a new class denoted by $\mathrm{R}$. The classes 2, 3 and 4 correspond to 2-fold rotations or composite two-fold operations and thus do not generate a new class. Only the class 5 which has a permutational orbit structure of length 4 (pure) is not a two-sided operation and thus (1324)R generates a new conjugacy class. The conjugacy classes for which the operation R produces equivalent operations double in number while those that do not produce equivalent operations produce new classes with equal number of elements as the original class. Thus for the $S_{2}\left[S_{2}\right]$ group the orders of conjugacy classes 2,3, and 4 double while the conjugacy classes 1 and 5 generate two 
new classes with the same number of elements as the original class. Once this has been identified, we can find the character values of the new irreducible representations of the double groups.

The character values of all even representations (single-valued) in the double group are identical to the values of the corresponding conjugacy classes before the multiplication of the R operation. New irreducible representations that equal the number of new conjugacy classes are generated and they correspond to double-valued or halfintegral irreducible representations. These new representations have to be even dimensional. This combined with the fact that the sum of the squares of the dimensions of these irreducible representations must add up to the order of the single group will provide us information on the dimensions of the new double valued representations. For the wreath product $\mathrm{S}_{2}\left[\mathrm{~S}_{2}\right]$, the case of $\mathrm{Tl}_{2} \mathrm{H}_{4}$, there should be two 2-dimenational doublevalued representations since $2^{2}+2^{2}=8$, the order of $S_{2}\left[S_{2}\right]$. The character values of these representations under the new conjugacy classes should be opposite in sign to the character values of the corresponding classes prior to multiplying by R. Also character values of all classes that double must be zero since we have

$$
\chi(p R)=-\chi(P),
$$

and since $\mathrm{p}$ and $\mathrm{pR}$ belong to the same class we have

$$
\chi(p R)=\chi(P),
$$

Thus combining the above two equations we get the result that the character value must be zero if $\mathrm{p}$ and $\mathrm{pR}$ belong to the same conjugacy class.

The character values of those classes that do not double can be obtained by identifying the rotational degree of the permutation operation and then by using the formula,

$$
\chi^{(j)}\left(C_{n}\right)=\frac{\sin \left(j+\frac{1}{2}\right)(2 \pi / n)}{\sin (\pi / n)}
$$

The first and the last irreducible representations, which are typically 2-dimensional, are obtained using the above formula. While the remaining ones are linear combination with the others to yield $\mathrm{D}^{(\mathrm{j})}$. This combined with the great orthogonality theorem uniquely 
determine the character values. Again the character values of the operations $\mathrm{pR}$ should have opposite in signs compared to the character values of $\mathrm{p}$.

As a first illustration for the double group of wreath product, consider the $\left\{\mathrm{S}_{2}\left[\mathrm{~S}_{2}\right]\right\}^{2}$ group of $\mathrm{Tl}_{2} \mathrm{H}_{4}$. Since only classes 1 and 5 do not double only two new classes are generated in the double group, which yield 2 irreducible representations for the double group $\left\{\mathrm{S}_{2}\left[\mathrm{~S}_{2}\right]\right\}^{2}$. These 2 irreducible representations have to be 2-dimensional to comply with the stipulation that sum of the squares of the dimensions must be 8 . The two irreducible representations can be thus denoted as $\mathrm{E}_{1 / 2}$ and $\mathrm{E}_{3 / 2}$. Both of these representations should have non-zero character values only under the classes 1, 5 and the new double group classes. The character values under the identity operation have already been determined as 2 for both of those. The character values under class 5 are determined using the formula above for $\chi^{(j)}$.

Once the character values of the double-valued representations have been determined, we can find the character table of the whole permutation-inversion double group. For the example of $\mathrm{Tl}_{2} \mathrm{H}_{4}$, since the double group of the PI group is a direct product of $\left\{\mathrm{S}_{2}\left[\mathrm{~S}_{2}\right]\right\}^{2}$ with the inversion group, the full character table is constructed as a direct product of the two tables. The entire character table of $\left\{\mathrm{S}_{2}\left[\mathrm{~S}_{2}\right] \times \mathrm{I}\right\}^{2}$ is shown in Table 2. The + and - super labels correspond to the parities of the representations relative to the inversion operation.

The character tables of the double groups of non-rigid molecules grow quickly and exponentially. Consider analogues of the ethane molecule such as hexamethyl dilead, Digermane $\left(\mathrm{Ge}_{2} \mathrm{H}_{6}\right), \mathrm{Sn}_{2} \mathrm{H}_{6}$ etc. For example, Pyykkö ${ }^{25}$ has considered the nuclear spinspin coupling constants of $\mathrm{Pb}_{2}\left(\mathrm{CH}_{3}\right)_{6}$ ' which exhibits ethane-like structure. The ground state of digermane is known to be $\mathrm{D}_{3 \mathrm{~d}}$ for its rigid equilibrium structure. The internal rotation around the $\mathrm{Pb}-\mathrm{Pb}$ bond would lead to $\mathrm{q}$ non-rigid group and non-rigid NMR group. Thus we consider the double group of the wreath product $S_{2}\left[S_{3}\right]$, which we denote by $\left\{S_{2}\left[S_{3}\right]\right\}^{2}$, where $S_{3}$ is the permutation group that contains 3 ! permutation of 3 objects. The conjugacy classes of the $\mathrm{S}_{2}\left[\mathrm{~S}_{3}\right]$ group are shown in Table III with those classes that generate new classes in the double group upon multiplication by $\mathrm{R}$. The classes are characterized by $3 \times 2$ matrices since there are 3 conjugacy classes in the $S_{3}$ group and 2 $\mathrm{Pb}$ nuclei. For each class we have also provided the overall permutation of the carbon 
nuclei for $\mathrm{Pb}_{2}\left(\mathrm{CH}_{3}\right)_{6}$. Thus the classes 1, 3, 5, 6, 8 and 9 generate new classes upon multiplication by $\mathrm{R}$ on the basis of their cycle structures and equivalent rotational operations. The remaining classes, which are two-sided double, and thus the character values for these classes in the double-values representations are zero. Table 3 also shows the order of each conjugacy class as obtained by the formulae that we discussed before. There are 9 conjugacy classes in $S_{2}\left[S_{3}\right]$ and 15 conjugacy classes in the double group, $\left\{\mathrm{S}_{2}\left[\mathrm{~S}_{3}\right]\right\}^{2}$.

Since there are 6 new conjugacy classes in the $\left\{S_{2}\left[S_{3}\right]\right\}^{2}$ double group, there should be six new double-valued representations in the double group. The dimensions of the even-dimensional representations should satisfy, $l_{1}^{2}+l_{2}^{2}+\ldots .+l_{6}^{2}=72$, and thus only possible solution with the above constraints is two 2-dimensional and four 4-dimensional irreducible representations should be present in the $\left\{\mathrm{S}_{2}\left[\mathrm{~S}_{3}\right]\right\}^{2}$ double group. Since the character values of the classes that double must be zero, we need to determine the character values of only classes $1,3,5,6,8$, and 9 . The first class has the character value equal to the dimension of the representation. The character values of the sixth, eighth and ninth representations are irrational and given by the character formulae. The characters of the class 3 and 5 are also obtained by identifying them with the appropriate rotational operations. In addition we have developed a computer code to ensure compliance of the great orthogonality theorem in the double group. The character values of the new conjugacy classes are the same as those of the corresponding classes without the $\mathrm{R}$ operation multiplied by -1 . The character table thus constructed for the $\left\{S_{2}\left[S_{3}\right]\right\}^{2}$ double group, which contains 144 operations, is shown in Table IV. If the inversion operation needs to be included the whole double group of the PI group is a direct product in this case, and would contain 288 operations. Note that in Table IV, the double-valued irreducible representations are denoted by underlines below the labels. Generation of the character table of the $\left\{\mathrm{S}_{2}\left[\mathrm{~S}_{3}\right]\right\}^{2}$ double group turned out to be tedious as we had to ensure of the places that have irrational characters and also compliance with the great orthogonality theorem.

As next case we consider the $\left\{\mathrm{S}_{4}\left[\mathrm{~S}_{2}\right]\right\}^{2}$ double group which as $2.4 ! .2^{4}=768$ operations. The $S_{4}\left[S_{2}\right]$ wreath product group occurs in number of other chemistry and physics applications, as it is the octahedral group in the fourth-dimension ${ }^{18,19}$ and also the 
orthogonal group in the fourth dimension. In the context of molecules containing very heavy atoms, Klinkhammer and Pyykkö ${ }^{24}$ and coworkers have shown that the dimerization energies for molecules such as $\left(\mathrm{BiH}_{2}\right)_{2},(\mathrm{H}-\mathrm{Po}-\mathrm{PoH})_{2}$, etc, are quite small in the range of 8 to $13 \mathrm{~kJ} / \mathrm{mole}$. This means a cluster such as $\left(\mathrm{TeH}_{2}\right)_{4}$ or $\left(\mathrm{PoH}_{2}\right)_{4}$ would be quite non-rigid due to the low intermolecular binding energy. This is consistent with the observed liquid state of $\mathrm{PoH}_{2}$. The symmetry group of any such non-rigid molecule would be characterized by the $\mathrm{S}_{4}\left[\mathrm{~S}_{2}\right]$ group in the absence of spin-orbit coupling. Once spin-orbit coupling is introduced into the hamiltonian, the relativistic spinor representation requires the $\left\{\mathrm{S}_{4}\left[\mathrm{~S}_{2}\right]\right\}^{2}$ double group for the treatment of rovibronic levels of such clusters which typically undergo tunneling in the higher group. With these species in mind, we have obtained the character table of the $\left\{\mathrm{S}_{4}\left[\mathrm{~S}_{2}\right]\right\}^{2}$ double group.

Table $\mathrm{V}$ shows the conjugacy classes of the $\mathrm{S}_{4}\left[\mathrm{~S}_{2}\right]$ group in terms of matrix cycle types. Since there are only 2 conjugacy classes in the $S_{2}$ group and $S_{4}$ acts on 4 objects, the cycle type matrices are $2 \times 4$, as seen from table $\mathrm{V}$. The ordered partitions of 4 into 2 parts are $(4,0),(0,4),(3,1),(1,3)$, and $(2,2)$. From these the number of conjugacy classes of $\mathrm{S}_{4}\left[\mathrm{~S}_{2}\right]$ is generated as $\mathrm{P}(4)+\mathrm{P}(4)+\mathrm{P}(3) \mathrm{P}(1)+\mathrm{P}(1) \mathrm{P}(3)+\mathrm{P}(2) \mathrm{P}(2)$, where $\mathrm{P}(\mathrm{m})$ is the number of partitions of the integer $\mathrm{m}$. Since $\mathrm{P}(4)=5, \mathrm{P}(3)=3$ and $\mathrm{P}(2)=2$, we get, $5+5+3+3+2 \times 2=20$. For each of the 20 conjugacy classes the matrix for the cycle types are constructed and are shown in Table V. From each of the matrix types, the number of elements in the conjugacy class is directly obtained using the formulae discussed before. The results are shown in Table V.

The conjugacy classes of the $\left\{\mathrm{S}_{4}\left[\mathrm{~S}_{2}\right]\right\}^{2}$ double group are obtained by identifying those classes that would generate new conjugacy classes when multiplied by the $\mathrm{R}$ operation. These are identified in Table $\mathrm{V}$ as classes 1, 9, 12,17, and 20. This was accomplished by identifying the proper/improper rotational operations of the permutations of protons of $\left(\mathrm{PoH}_{2}\right)_{4}$. These permutational orbit structures are shown in Table $\mathrm{V}$ for eight protons. The classes 1,9,12,17 and 20 have structures $1^{8}, 1^{4} 4,1^{2} 3^{2}, 8$ and $4^{2}$, and also they correspond to proper or improper rotations of the corresponding orbit foldness. It is interesting to observe that these five classes can be represented by Young Tableau of the five partitions of the integer 4 . Thus these conjugacy classes generate new classes upon multiplication by R. All other conjugacy classes of the 
$\left\{\mathrm{S}_{4}\left[\mathrm{~S}_{2}\right]\right\}^{2}$ double group double and thus their character values for the double-valued irreducible representations are zero.

The character table of the $\left\{\mathrm{S}_{4}\left[\mathrm{~S}_{2}\right]\right\}^{2}$ double group is constructed first by obtaining the character table of $\mathrm{S}_{4}\left[\mathrm{~S}_{2}\right]$ and then finding the double-valued irreducible representations in the double group. The irreducible representations of the $S_{2}\left[S_{4}\right]$ group, their labels and dimensions are shown in Table VI. These irreducible representations were obtained by constructing unique outer tensor products of four copies of irreducible representations of $S_{2}$, then finding the inertia factor groups, and finally multiplying the inertia factor group representations as inner products. The final representation is induced over the whole group.

The actual character values of the single-valued irreducible representations are constructed first by using the combinatorial matrix type generators. We shall consider this for two illustrative examples. First let us consider the $\mathrm{E}_{2}$ irreducible representation given by $\left(\left[1^{2}\right] \#\left[1^{2}\right] \#\left[1^{2}\right] \#\left[1^{2}\right]\right) \otimes\left[2^{2}\right]^{\prime}$. The GCCI of the $\left[2^{2}\right]^{\prime}$ representation and the various matrix type expressions are shown below:

$$
\begin{aligned}
& P_{S_{4}}^{\left[2^{2}\right]}=\frac{1}{24}\left[2 s_{1}^{4}-8 s_{1} s_{3}+6 s_{2}^{2}\right] \\
& T(M)_{1}=\frac{1}{2}\left\{\left[\begin{array}{llll}
1 & 0 & 0 & 0 \\
0 & 0 & 0 & 0
\end{array}\right]-\left[\begin{array}{llll}
0 & 0 & 0 & 0 \\
1 & 0 & 0 & 0
\end{array}\right]\right\} \\
& T(M)_{2}=\frac{1}{2}\left\{\left[\begin{array}{llll}
0 & 1 & 0 & 0 \\
0 & 0 & 0 & 0
\end{array}\right]-\left[\begin{array}{llll}
0 & 0 & 0 & 0 \\
0 & 1 & 0 & 0
\end{array}\right]\right\} \\
& T(M)_{3}=\frac{1}{2}\left\{\left[\begin{array}{llll}
0 & 0 & 1 & 0 \\
0 & 0 & 0 & 0
\end{array}\right]-\left[\begin{array}{llll}
0 & 0 & 0 & 0 \\
0 & 0 & 1 & 0
\end{array}\right]\right\} \\
& T(M)_{4}=\frac{1}{2}\left\{\left[\begin{array}{llll}
0 & 0 & 0 & 1 \\
0 & 0 & 0 & 0
\end{array}\right]-\left[\begin{array}{llll}
0 & 0 & 0 & 0 \\
0 & 0 & 0 & 1
\end{array}\right]\right\}
\end{aligned}
$$

Next we replace every $\mathrm{s}_{\mathrm{k}}$ in $P_{S_{4}}^{\left[2^{2}\right]}$ by $\mathrm{T}(\mathrm{M})_{\mathrm{k}}$ we obtain, 


$$
\frac{1}{4 ! 2^{4}}\left\{\begin{array}{l}
2\left[\left[\begin{array}{llll}
1 & 0 & 0 & 0 \\
0 & 0 & 0 & 0
\end{array}\right]-\left[\begin{array}{llll}
0 & 0 & 0 & 0 \\
1 & 0 & 0 & 0
\end{array}\right]\right]^{4}-32\left[\left[\begin{array}{llll}
1 & 0 & 0 & 0 \\
0 & 0 & 0 & 0
\end{array}\right]-\left[\begin{array}{cccc}
0 & 0 & 0 & 0 \\
1 & 0 & 0 & 0
\end{array}\right]\right] \times\left[\begin{array}{llll}
0 & 0 & 1 & 0 \\
0 & 0 & 0 & 0
\end{array}\right]-\left[\begin{array}{llll}
0 & 0 & 0 & 0 \\
0 & 0 & 1 & 0
\end{array}\right] \\
+24\left[\left[\begin{array}{llll}
0 & 1 & 0 & 0 \\
0 & 0 & 0 & 0
\end{array}\right]-\left[\begin{array}{llll}
0 & 0 & 0 & 0 \\
0 & 1 & 0 & 0
\end{array}\right]\right]^{2}
\end{array}\right\}
$$

The above expression upon simplification of the various terms yields

$$
\begin{aligned}
& P^{E_{2}}=\frac{1}{4 ! 2^{4}}\left\{2\left[\begin{array}{llll}
4 & 0 & 0 & 0 \\
0 & 0 & 0 & 0
\end{array}\right]-8\left[\begin{array}{llll}
3 & 0 & 0 & 0 \\
1 & 0 & 0 & 0
\end{array}\right]+12\left[\begin{array}{llll}
2 & 0 & 0 & 0 \\
2 & 0 & 0 & 0
\end{array}\right]-8\left[\begin{array}{llll}
1 & 0 & 0 & 0 \\
3 & 0 & 0 & 0
\end{array}\right]+2\left[\begin{array}{llll}
0 & 0 & 0 & 0 \\
4 & 0 & 0 & 0
\end{array}\right]-32\left[\begin{array}{llll}
1 & 0 & 1 & 0 \\
0 & 0 & 0 & 0
\end{array}\right]\right. \\
& \left.+32\left[\begin{array}{llll}
0 & 0 & 1 & 0 \\
1 & 0 & 0 & 0
\end{array}\right]+32\left[\begin{array}{llll}
1 & 0 & 0 & 0 \\
0 & 0 & 1 & 0
\end{array}\right]-32\left[\begin{array}{llll}
0 & 0 & 0 & 0 \\
1 & 0 & 1 & 0
\end{array}\right]+24\left[\begin{array}{llll}
0 & 2 & 0 & 0 \\
0 & 0 & 0 & 0
\end{array}\right]-48\left[\begin{array}{llll}
0 & 1 & 0 & 0 \\
0 & 1 & 0 & 0
\end{array}\right]+24\left[\begin{array}{llll}
0 & 0 & 0 & 0 \\
0 & 2 & 0 & 0
\end{array}\right]\right\}
\end{aligned}
$$

The string of coefficients $\{2,-8,12,-8,2,0,0,0,0,0,0,-32,32,32,-32,0,0,24,-48,24\}$ in the above expression for in the order of 20 conjugacy classes in Table $\mathrm{V}$ yields the character values times the number of elements in the respective conjugacy classes. Once the orders of the conjugacy classes are factored out we obtain the character string values $\{2,-2,2,-2,2,0,0,0,0,0,0,-1,1,1,-$ $1,0,0,2,-2,2\}$ for all 20 conjugacy classes of the wreath product $S_{4}\left[S_{2}\right]$.

As another example consider the $\mathrm{K}_{2}$ irreducible representation (8-dimensional). Since it is given by $\left(\left[1^{2}\right] \#\left[1^{2}\right] \#\left[1^{2}\right]\right) \otimes[21]^{\prime} \#\left([2] \otimes[1]^{\prime}\right.$ the character generator is given by

$$
\begin{aligned}
& \frac{1}{4 ! 2^{4}}\left\{8\left[\left[\begin{array}{llll}
1 & 0 & 0 & 0 \\
0 & 0 & 0 & 0
\end{array}\right]-\left[\begin{array}{cccc}
0 & 0 & 0 & 0 \\
1 & 0 & 0 & 0
\end{array}\right]\right]^{3}-32\left[\begin{array}{llll}
0 & 0 & 1 & 0 \\
0 & 0 & 0 & 0
\end{array}\right]-\left[\begin{array}{llll}
0 & 0 & 0 & 0 \\
0 & 0 & 1 & 0
\end{array}\right]\right\} \\
& \times\left\{\left[\begin{array}{llll}
1 & 0 & 0 & 0 \\
0 & 0 & 0 & 0
\end{array}\right]+\left[\begin{array}{llll}
0 & 0 & 0 & 0 \\
1 & 0 & 0 & 0
\end{array}\right]\right\}
\end{aligned}
$$

The above expression upon simplification yields

$$
\begin{aligned}
& P^{K_{2}}=\frac{1}{4 ! 2^{4}}\left\{8\left[\begin{array}{llll}
4 & 0 & 0 & 0 \\
0 & 0 & 0 & 0
\end{array}\right]-16\left[\begin{array}{llll}
3 & 0 & 0 & 0 \\
1 & 0 & 0 & 0
\end{array}\right]+16\left[\begin{array}{llll}
1 & 0 & 0 & 0 \\
3 & 0 & 0 & 0
\end{array}\right]-8\left[\begin{array}{llll}
0 & 0 & 0 & 0 \\
4 & 0 & 0 & 0
\end{array}\right]-32\left[\begin{array}{cccc}
1 & 0 & 1 & 0 \\
0 & 0 & 0 & 0
\end{array}\right]\right. \\
& \left.-32\left[\begin{array}{llll}
0 & 0 & 1 & 0 \\
1 & 0 & 0 & 0
\end{array}\right]+32\left[\begin{array}{llll}
1 & 0 & 0 & 0 \\
0 & 0 & 1 & 0
\end{array}\right]+32\left[\begin{array}{llll}
0 & 0 & 0 & 0 \\
1 & 0 & 1 & 0
\end{array}\right]\right\}
\end{aligned}
$$


From the above expression we infer the coefficient string $\{8,-16,0,16,-8,0,0,0,0,0,0,-32$, $32,32,32,0,0,0,0,0\}$ which yields the character value string of $\{8,-4,0,4,-8,0,0,0,0,0,0,-1$, $-1,1,1,0,0,0,0,0\}$.

The double valued irreducible representations are enumerated using the fact that there must be exactly five double-valued irreducible representations since 5 new conjugacy classes are created. The dimensions of these 5 irreducible representations must satisfy

$$
\ell_{1}^{2}+\ell_{2}^{2}+\ell_{3}^{2}+\ell_{4}^{2}+\ell_{5}^{2}=384
$$

and the only possible solution is $\ell_{1}=4, \ell_{2}=4, \ell_{3}=8, \ell_{4}=12, \ell_{5}=12$ in the ascending order of dimensionalities. This determined that the dimensions of the doubled-valued irreducible representations of the $\left\{\mathrm{S}_{4}\left[\mathrm{~S}_{2}\right]\right\}^{2}$ double group should be $4,4,8,12$ and 12 . We denoted these irreducible representations by $\underline{\mathrm{G}}_{1}, \underline{\mathrm{G}}_{2}, \underline{\mathrm{K}}, \mathrm{O}_{1}, \underline{\mathrm{O}}_{2}$, where the underscore represents that it is two-valued representation.

The character values of the new double-valued representations are determined by finding the character values of five classes 1,9,12,17 and 20 using the double-valued character formulae. All other classes should have zero character values due to the fact these conjugacy classes double. The character values of classes 9 and 17 are irrational numbers as expected for these higher order rotational operations. Once these character values are generated the remaining character values, which are integral, correspond to classes 12 and 20. Of course the character value of class 1 is the dimension of the irreducible representation of the two-valued representation, which we have already determined. The character values of the five new conjugacy classes in the double group are determined as the character values of the corresponding classes without multiplying by $R$ and then multiplying the value by -1 .

Table VII shows the character table of the $\left\{\mathrm{S}_{4}\left[\mathrm{~S}_{2}\right]\right\}^{2}$ double group as obtained using the repeated application of the above procedure for all 25 irreducible representations. The two-valued representations have underlines below the labels to contrast them from the singled-valued irreducible representations. The orthogonality of every row of the character table with every other row was rigorously checked by a computer code that we developed for orthogonality check. It is interesting to note that 
unlike other lower order groups the smallest double-valued irreducible representation is four-dimensional in the $\left\{\mathrm{S}_{4}\left[\mathrm{~S}_{2}\right]\right\}^{2}$ double group.

\section{Nuclear spin statistics, Spinor Representations, Tunneling Splittings of rotational/rovibronic levels and of Non-rigid molecules with very heavy atoms.}

The character tables of the non-rigid groups thus constructed can be used in number of applications such as nuclear spin statistics, correlation of rovibronic levels including half-integral quantum numbers, and in spinor representations. As a first case let us illustrate the use of the table in finding the nuclear spin multiplets. Consider $\left(\mathrm{PoH}_{2}\right)_{4}$ and $\left(\mathrm{PoD}_{2}\right)_{4}$ as examples. Let us represent three $\mathrm{m}_{\mathrm{s}}$ functions of the $\mathrm{D}$ nucleus by $\lambda, \mu$, and $v$, where these labels represent $m s=-1,0$ and +1 , respectively. For example, from the character table VII, we can obtain the GGCI of the representation $\mathrm{K}_{1}$ as

$$
P_{G}^{K_{1}}=\frac{1}{384}\left[8 s_{1}^{8}+16 s_{1}^{6} s_{2}-16 s_{1}^{2} s_{2}^{3}-8 s_{2}^{4}-32 s_{1}^{2} s_{3}^{2}+32 s_{2} s_{3}^{2}-32 s_{1}^{2} s_{6}+32 s_{2} s_{6}\right]
$$

The ${ }^{3} \mathrm{D}$ nuclear spin generating function is obtained by replacing every $\mathrm{s}_{\mathrm{k}}$ in the above expression by $\left(\lambda^{\mathrm{k}}+\mu^{\mathrm{k}}+v^{\mathrm{k}}\right)$. Thus we obtain

$$
\left.\begin{array}{l}
P^{K_{1}}=\frac{1}{384}\left[8(\lambda+\mu+v)^{8}+16(\lambda+\mu+v)^{6}\left(\lambda^{2}+\mu^{2}+v^{2}\right)-16(\lambda+\mu+v)^{2}\left(\lambda^{2}+\mu^{2}+v^{2}\right)^{3}\right. \\
-8\left(\lambda^{2}+\mu^{2}+v^{2}\right)^{4}-32(\lambda+\mu+v)^{2}\left(\lambda^{3}+\mu^{3}+v^{3}\right)^{2}+32\left(\lambda^{2}+\mu^{2}+v^{2}\right)\left(\lambda^{3}+\mu^{3}+v^{3}\right)^{2} \\
-32(\lambda+\mu+v)^{2}\left(\lambda^{6}+\mu^{6}+v^{6}\right)+32\left(\lambda^{2}+\mu^{2}+v^{2}\right)\left(\lambda^{6}+\mu^{6}+v^{6}\right)
\end{array}\right]
$$

The coefficient of a typical term $\lambda^{i} \mu^{j} v^{k}$ yields the number of ${ }^{3} \mathrm{D}$ nuclear spin functions containing i spin functions with $\mathrm{m}_{\mathrm{s}=-1}, \mathrm{j}$ functions with $\mathrm{m}_{\mathrm{s}=0}$ and $\mathrm{k}$ spin functions with $\mathrm{m}_{\mathrm{s}}=+1$ that transform as the $\mathrm{K}_{1}$ irreducible representation. Once these generating functions are constructed for each of the irreducible representations of the group, then the irreducible representations are for the spin functions can be sorted according to their total $M_{F}$ nuclear spin quantum numbers. The results would be all the spin multiplets and the number of times each spin multiplet would occur in a given irreducible representation. The results thus obtained are shown in Table VIII for both ${ }^{3} \mathrm{D}$ and ${ }^{2} \mathrm{H}$ species. 
As seen from Table VIII, the proton species are much fewer compared to the deuterium spin species. By multiplying the spin multiplicity by the frequency of each multiplet and adding the numbers we get the frequencies of the various irreducible representations in the group. Thus

$$
\begin{aligned}
& \Gamma_{H}=15 A_{1}+A_{3}+6 E_{1}+15 T_{1}+3 T_{2}+10 G_{1}+G_{2}+3 G_{3}+6 I_{1}+3 I_{3}+8 K_{1} \\
& \Gamma_{D}=126 A_{1}+15 A_{2}+15 A_{3}+105 E_{1}+6 E_{2}+210 T_{1}+105 T_{2}+15 T_{3}+3 T_{4}+168 G_{1}+60 G_{2} \\
& +60 G_{3}+6 G_{4}+126 I_{1}+63 I_{2}+90 I_{3}+45 I_{4}+210 K_{1}+48 K_{2}
\end{aligned}
$$

In the case of protons, which are fermions, the overall wavefunction must be antisymmetric and thus the total wave function must transform as $\mathrm{A}_{3}$ and thus the nuclear spin statistical weights of the rovibronic levels are $A_{1}(1), A_{3}(15), E_{2}(6), T_{3}(15), T_{4}(3)$, $\mathrm{G}_{1}(3), \mathrm{G}_{3}(10), \mathrm{G}_{4}(1), \mathrm{I}_{1}(6), \mathrm{I}_{3}(3), \mathrm{K}_{2}(8)$. The nuclear spin statistic weights of the proton species are the same as the frequencies since they are bosons.

The tunneling splittings of the rovibronic levels can be obtained using the double group character table. The overall rovibronic species is the direct product of electronic, vibrational and rotational species. The overall rovibronic species is first correlated in the normal rigid subgroup. Then using the induced representation theory the irreducible representation from the rigid group is correlated into the non-rigid molecular group. We can illustrate this with $\mathrm{Tl}_{2} \mathrm{H}_{4}$ as the first example. Since the rigid molecule has an equilibrium geometry of $\mathrm{D}_{2 \mathrm{~d}}$ we start with the correlation of the rovibronic levels as a function of the total $\mathrm{K}$ quantum number. Since the ground electronic state of $\mathrm{Tl}_{2} \mathrm{H}_{4}$ is a ${ }^{1} \mathrm{~A}_{1}$ state, the overall $\mathrm{K}$ values are integral and thus integral quantum number correlations suffice. Table IX shows such a correlation table for both integral and half-integral values of $\mathrm{K}$. As seen from Table IX even in the ground rovibronic state $\mathrm{Tl}_{2} \mathrm{H}_{4}$ exhibits tunneling splitting into $\mathrm{A}_{1}{ }^{+}+\mathrm{A}_{1}{ }^{-}$tunneling levels. Excited rovibronic levels show more complex tunneling splittings as demonstrated in Table IX. For all radical species the half-integral correlations are appropriate. For example, removal of an electron from $\mathrm{Tl}_{2} \mathrm{H}_{4}$ to form $\mathrm{Tl}_{2} \mathrm{H}_{4}{ }^{+}$results in a doublet ground electronic state. Thus the group state of $\mathrm{Tl}_{2} \mathrm{H}_{4}{ }^{+}$ correlates into $E_{1 / 2}$ representation for the rigid species, which splits into $E_{1 / 2}{ }^{+}+E_{1 / 2}{ }^{-}$ tunneling levels. Likewise the excited rovibronic levels follow the pattern in Table IX for 
half-integral quantum numbers. We have included both half-integral and integral representations in the correlation table for completeness.

\section{Conclusion}

The spinor double groups of non-rigid molecules that contain heavy atoms and also exhibit large amplitude motions wire considered. It was shown that their groups are double groups of wreath product groups. Several examples of double groups of wreath products such as $\left\{\mathrm{S}_{2}\left[\mathrm{~S}_{2}\right] \mathrm{xI}\right\}^{2},\left\{\mathrm{~S}_{2}\left[\mathrm{~S}_{3}\right]\right\}^{2},\left\{\mathrm{~S}_{4}\left[\mathrm{~S}_{2}\right]\right\}^{2}$, etc., were considered as representatives of non-rigid $\mathrm{Tl}_{2} \mathrm{H}_{4}, \mathrm{~Pb}_{2}\left(\mathrm{CH}_{3}\right)_{6}$, $\left(\mathrm{PoH}_{2}\right)_{4}$, etc. It was shown that the conjugacy classes of these groups could be characterized by matrix cycle types. Combinatorial generating functions were considered using the matrix type polynomials. Coefficients in the generating functions were shown to yield the character values of single-valued irreducible representations. The double-valued irreducible representations were obtained by first identifying which conjugacy classes generate new conjugacy classes under the operation $\mathrm{R}$. Then the character values of these classes were systematically obtained. We have derived the character tables of all these double groups that included up to 768 elements We also presented a few representative applications of the double groups in generating the nuclear spin species of these species and nuclear spin statistical weights. We showed the use of these tables for the correlation of rovibronic levels of non-rigid species into tunneling levels for both integral and half-integral quantum numbers. The tables with double valued representations are useful for both electronic states with integral and half-integral spin multiplicities for which spin-orbit coupling can mix different electronic states as determined by their symmetries in the double group. We illustrated the construction and application of the correlation table for the rovibronic levels for the $\mathrm{Tl}_{2} \mathrm{H}_{4}$ case. Construction of the correlation tables for other species can be done as necessary using the character tables, and such applications could be the topic of future studies. 


\section{Acknowledgement}

This research was performed under the auspices of the US department of Energy by the University of California, LLNL under contract number W-7405-Eng-48 while the work at UC Davis was supported by National Science Foundation.

\section{References}

${ }^{1}$ P. Pyykkö, Relativistic Theory of Atoms and Molecules, Springer Verlag: Berlin and New York, Part I 1986 Part II 1993, Part 3 2000. For comprehensive list of references up to 2002 see http://www.csc.fi/rtam/.

${ }^{2}$ H.T. Toivonen and P. Pyykkö, International J. Quantum Chemistry, 11, 697 (1977)

${ }^{3}$ K. Balasubramanian, Relativistic Effects in Chemistry, Part A: Theory and Techniques, (Wiley-interscience, New York, NY, p301 1997).

${ }^{4}$ H.T. Toivonen and P. Pyykkö: Relativistic molecular orbitals and representation matrices for the double groups $\mathbf{T}$ and $\mathrm{T}_{\mathrm{h}}$, Department of Physical Chemistry, Åbo Akademi, Finland, Report No. B79 (1977), 11 p

${ }^{5}$ K. Balasubramanian, Chemical Physics Letters 260, 484 (1996).

${ }^{6}$ S L Altmann and P Herzig, Mol. Phys.45, 585 (1982); S L Altmann and P Herzig, PointGroup Theory Tables, (Clarendon Press, Oxford, 1994).

${ }^{7}$ M. Hamermesh, "Group Theory And its Applications to Physical Problems", AddisonWesley, Reading, MA,1964

${ }^{8}$ H. C. Longuet-Higgins, Mol. Phys. 6, 445. (1963)

${ }^{9}$ K. Balasubramanian, J. Chem. Phys. 72, 665(1980).

${ }^{10}$ K. Balasubramanian, Theoretica Chimica Acta, 78, 31(1990).

${ }^{11}$ K. Balasubramanian, J. Chem. Phys. 95, 8273(1991).

${ }^{12}$ K. Balasubramanian, J. Chem. Phys. 74, 6824(1981)

${ }^{13}$ K. Balasubramanian, J. Chem. Phys. 75, 4572(1981)

${ }^{14}$ K. Balasubramanian and T. R. Dyke, J. Phys. Chem., 88, 4688(1984). 
${ }^{15}$ K. Balasubramanian, in "Symmetries and Properties of non-rigid Molecules", Studies in Phys. Theor Chem. 243 (1983).

${ }^{16}$ K. Balasubramanian, Chemical Review 85, 599(1985).

${ }^{17}$ F. P. Temme, Chem. Phys. Lett. 200, 534(1992).

${ }^{18}$ R. B. King, Inorg. Chem. 20, 363(1981)

${ }^{19}$ R. B. King, Theor. Chim. Acta, 59, 25, (1981)

${ }^{20}$ F. Amar, M. E. Kelman, and R. S. Berry, J. Chem. Phys. 70, 1973 (1979)

${ }^{21}$ T. R. Dyke, Tpoc. Current Chem., 120, 85 (1983)

${ }^{22}$ J. A. Odutola, A. I. Avis, C. W. Curtis and T. R. Dyke, Mol. Phys. 42, 267 (1981)

${ }^{23}$ J. A. Odutola, T. A. Hu, D. Prinslow, and T. R. Dyke, J. Chem. Phys. 88, 5352 (1988)

${ }^{24}$ K. W. Klinkhammer and P. Pyykkö, Inorg. Chem. 24, 4134 (1995)

${ }^{25}$ P. Pyykkö, J. Organometallic Chem. 232, 21 (1981)

${ }^{26}$ D. E. Littlewood, "Theory of Group Representation and Matrix Product of Groups", (Clarendon, Oxford 1940).

${ }^{27} \mathrm{~K}$. Balasubramanian, Manuscript in preparation 
Table I Conjugacy Classes of the $S_{2}\left[S_{2}\right]$ group

\begin{tabular}{|l|l|l|l|}
\hline No & Matrix type & Permutation & $\begin{array}{l}\text { Number of } \\
\text { elements }\end{array}$ \\
\hline 1 & {$\left[\begin{array}{ll}2 & 0 \\
0 & 0\end{array}\right]$} & $(1)(2)(3)(4)$ & $1^{\dagger}$ \\
\hline 2 & {$\left[\begin{array}{ll}0 & 0 \\
2 & 0\end{array}\right]$} & $(12)(34)$ & 1 \\
\hline 3 & {$\left[\begin{array}{ll}1 & 0 \\
1 & 0\end{array}\right]$} & $(1)(2)(34)$ & 2 \\
\hline 4 & {$\left[\begin{array}{ll}0 & 1 \\
0 & 0\end{array}\right]$} & $(13)(24)$ & 2 \\
\hline 5 & {$\left[\begin{array}{ll}0 & 0 \\
0 & 1\end{array}\right]$} & $(1423)$ & $2^{\dagger}$ \\
\hline
\end{tabular}

${ }^{\dagger}$ Classes that generate new classes in the double group. 
Table II Character Table of $\left\{\mathrm{S}_{2}\left[\mathrm{~S}_{2}\right] \mathrm{xI}\right]^{2}$

\begin{tabular}{|l|l|l|l|l|l|l|l|l|l|l|l|l|l|l|}
\hline & $1^{4}$ & $2^{2}$ & $1^{2} 2$ & $2^{2}$ & 4 & $1^{4^{*}}$ & $2^{2^{*}}$ & $1^{2} 2^{*}$ & $2^{2} *$ & $4^{*}$ & $\mathrm{R} 1^{4}$ & $\mathrm{R} 4$ & $\mathrm{R} 1^{4} *$ & $\mathrm{R} 4^{*}$ \\
\hline & 1 & $1[2]$ & $2[4]$ & $2[4]$ & 2 & 1 & $1[2]$ & $2[4]$ & $2[4]$ & 2 & 1 & 2 & 1 & 2 \\
\hline $\mathrm{A}_{1}{ }^{+}$ & 1 & 1 & 1 & 1 & 1 & 1 & 1 & 1 & 1 & 1 & 1 & 1 & 1 & 1 \\
\hline $\mathrm{A}_{2}{ }^{+}$ & 1 & 1 & -1 & -1 & 1 & 1 & 1 & -1 & -1 & 1 & 1 & 1 & 1 & 1 \\
\hline $\mathrm{B}_{1}{ }^{+}$ & 1 & 1 & -1 & 1 & -1 & 1 & 1 & -1 & 1 & -1 & 1 & -1 & 1 & -1 \\
\hline $\mathrm{B}_{2}{ }^{+}$ & 1 & 1 & 1 & -1 & -1 & 1 & 1 & 1 & -1 & -1 & 1 & -1 & 1 & -1 \\
\hline $\mathrm{A}_{1}{ }^{-}$ & 1 & 1 & 1 & 1 & 1 & -1 & -1 & -1 & -1 & -1 & -1 & -1 & -1 & -1 \\
\hline $\mathrm{A}_{2}^{-}$ & 1 & 1 & -1 & -1 & 1 & -1 & -1 & 1 & 1 & -1 & -1 & -1 & -1 & -1 \\
\hline $\mathrm{B}_{1}{ }^{-}$ & 1 & 1 & -1 & 1 & -1 & -1 & -1 & 1 & -1 & 1 & -1 & 1 & -1 & 1 \\
\hline $\mathrm{B}_{2}^{-}$ & 1 & 1 & 1 & -1 & -1 & -1 & -1 & -1 & 1 & 1 & -1 & 1 & -1 & 1 \\
\hline $\mathrm{E}^{+}$ & 2 & -2 & 0 & 0 & 0 & 2 & -2 & 0 & 0 & 0 & 2 & 0 & 2 & 0 \\
\hline $\mathrm{E}^{-}$ & 2 & -2 & 0 & 0 & 0 & -2 & 2 & 0 & 0 & 0 & 2 & 0 & -2 & 0 \\
\hline $\mathrm{E}_{1 / 2}{ }^{+}$ & 2 & 0 & 0 & 0 & $\sqrt{ } 2$ & 2 & 0 & 0 & 0 & $\sqrt{ } 2$ & -2 & $-\sqrt{ } 2$ & -2 & $-\sqrt{ } 2$ \\
\hline $\mathrm{E}_{3 / 2}{ }^{+}$ & 2 & 0 & 0 & 0 & $-\sqrt{ } 2$ & 2 & 0 & 0 & 0 & $-\sqrt{ } 2$ & -2 & $\sqrt{ } 2$ & -2 & $\sqrt{ } 2$ \\
\hline $\mathrm{E}_{1 / 2}{ }^{-}$ & 2 & 0 & 0 & 0 & $\sqrt{ } 2$ & -2 & 0 & 0 & 0 & $-\sqrt{ } 2$ & -2 & $-\sqrt{ } 2$ & 2 & $\sqrt{ } 2$ \\
\hline $\mathrm{E}_{3 / 2}{ }^{-}$ & 2 & 0 & 0 & 0 & $-\sqrt{ } 2$ & -2 & 0 & 0 & 0 & $\sqrt{ } 2$ & -2 & $\sqrt{ } 2$ & 2 & $-\sqrt{ } 2$ \\
\hline
\end{tabular}


Table III Conjugacy Classes of the $\mathrm{S}_{2}\left[\mathrm{~S}_{3}\right]$ group

\begin{tabular}{|c|c|c|c|c|c|c|c|}
\hline No & $\begin{array}{l}\text { Matrix } \\
\text { type }\end{array}$ & Permutation & $\begin{array}{l}\text { Number } \\
\text { of } \\
\text { elements }\end{array}$ & No & $\begin{array}{l}\text { Matrix } \\
\text { type }\end{array}$ & Permutation & $\begin{array}{l}\text { Number } \\
\text { of } \\
\text { elements }\end{array}$ \\
\hline $1^{\dagger}$ & {$\left[\begin{array}{ll}2 & 0 \\
0 & 0 \\
0 & 0\end{array}\right]$} & $1^{6}$ & 1 & 2 & {$\left[\begin{array}{ll}1 & 0 \\
1 & 0 \\
0 & 0\end{array}\right]$} & $1^{4} 2$ & 6 \\
\hline $3^{\dagger}$ & {$\left[\begin{array}{ll}1 & 0 \\
0 & 0 \\
1 & 0\end{array}\right]$} & $1^{3} 3$ & 4 & 4 & {$\left[\begin{array}{ll}0 & 0 \\
2 & 0 \\
0 & 0\end{array}\right]$} & $1^{2} 2^{2}$ & 9 \\
\hline $5^{\dagger}$ & {$\left[\begin{array}{ll}0 & 0 \\
0 & 0 \\
2 & 0\end{array}\right]$} & $3^{2}$ & 4 & $6^{\dagger}$ & {$\left[\begin{array}{ll}0 & 0 \\
1 & 0 \\
1 & 0\end{array}\right]$} & 123 & 12 \\
\hline 7 & {$\left[\begin{array}{ll}0 & 1 \\
0 & 0 \\
0 & 0\end{array}\right]$} & $2^{3}$ & 6 & $8^{\dagger}$ & {$\left[\begin{array}{ll}0 & 0 \\
0 & 0 \\
0 & 1\end{array}\right]$} & 6 & 12 \\
\hline $9^{\dagger}$ & {$\left[\begin{array}{ll}0 & 0 \\
0 & 1 \\
0 & 0\end{array}\right]$} & 24 & 18 & & & & \\
\hline
\end{tabular}

${ }^{\dagger}$ Classes that generate new classes in the double group. 
Table IV Character table of $\left\{\mathrm{S}_{2}\left[\mathrm{~S}_{3}\right]\right\}^{2}$ double group

\begin{tabular}{|l|l|l|l|l|l|l|l|l|l|l|l|l|l|l|l|}
\hline Conj & 1 & $1^{4} 2$ & $1^{3}$ & $1^{2} 2^{2}$ & $3^{2}$ & $\begin{array}{l}12 \\
3\end{array}$ & $2^{3}$ & 6 & 24 & $\begin{array}{l}\mathrm{R} 1 \\
6\end{array}$ & $\begin{array}{l}\mathrm{R} \\
1^{3} 3\end{array}$ & $\begin{array}{l}\mathrm{R} 3 \\
2\end{array}$ & $\mathrm{R} 123$ & $\mathrm{R} 6$ & $\begin{array}{l}\mathrm{R} 2 \\
4\end{array}$ \\
\hline $\begin{array}{l}\text { Orde } \\
\mathrm{r}\end{array}$ & 1 & $6[12]$ & 4 & $9[18]$ & 4 & 12 & $6[12]$ & 12 & 18 & 1 & 4 & 4 & 12 & 12 & 18 \\
\hline $\mathrm{A}_{1}$ & 1 & 1 & 1 & 1 & 1 & 1 & 1 & 1 & 1 & 1 & 1 & 1 & 1 & 1 & 1 \\
\hline $\mathrm{A}_{2}$ & 1 & 1 & 1 & 1 & 1 & 1 & -1 & -1 & -1 & 1 & 1 & 1 & 1 & -1 & -1 \\
\hline $\mathrm{A}_{3}$ & 1 & -1 & 1 & 1 & 1 & -1 & -1 & -1 & 1 & 1 & 1 & 1 & -1 & -1 & 1 \\
\hline $\mathrm{A}_{4}$ & 1 & -1 & 1 & 1 & 1 & -1 & 1 & 1 & -1 & 1 & 1 & 1 & -1 & 1 & -1 \\
\hline $\mathrm{E}$ & 2 & 0 & 2 & -2 & 2 & 0 & 0 & 0 & 0 & 2 & 2 & 2 & 0 & 0 & 0 \\
\hline $\mathrm{G}_{1}$ & 4 & 0 & -2 & 0 & 1 & 0 & 2 & -1 & 0 & 4 & -2 & 2 & 0 & -1 & 0 \\
\hline $\mathrm{G}_{2}$ & 4 & 0 & -2 & 0 & 1 & 0 & -2 & 1 & 0 & 4 & -2 & 1 & 0 & 1 & 0 \\
\hline $\mathrm{G}_{3}$ & 4 & 2 & 1 & 0 & -2 & -1 & 0 & 0 & 0 & 4 & 1 & 1 & -1 & 0 & 0 \\
\hline $\mathrm{G}_{4}$ & 4 & -2 & 1 & 0 & -2 & 1 & 0 & 0 & 0 & 4 & 1 & -2 & 1 & 0 & 0 \\
\hline$\underline{\mathrm{E}}_{1}$ & 2 & 0 & -2 & 0 & 2 & 0 & 0 & $\sqrt{ } 3$ & 0 & -2 & 0 & 2 & 0 & $-\sqrt{3}$ & 0 \\
\hline$\underline{\mathrm{E}}_{2}$ & 2 & 0 & -2 & 0 & 2 & 0 & 0 & $-\sqrt{ } 3$ & 0 & -2 & 0 & 2 & 0 & $\sqrt{3}$ & 0 \\
\hline$\underline{\mathrm{G}}_{1}$ & 4 & 0 & 2 & 0 & 1 & 0 & 0 & 0 & $\sqrt{2}$ & -4 & -2 & -1 & 0 & 0 & $-\sqrt{2}$ \\
\hline$\underline{\mathrm{G}}_{2}$ & 4 & 0 & 2 & 0 & 1 & 0 & 0 & 0 & $-\sqrt{2}$ & -4 & -2 & -1 & 0 & 0 & $\sqrt{2}$ \\
\hline$\underline{\mathrm{G}}_{3}$ & 4 & 0 & -1 & 0 & -2 & $\sqrt{3}$ & 0 & 0 & 0 & -4 & 1 & 2 & $-\sqrt{3}$ & 0 & 0 \\
\hline$\underline{\mathrm{G}}_{4}$ & 4 & 0 & -1 & 0 & -2 & $-\sqrt{3}$ & 0 & 0 & 0 & -4 & 1 & 2 & $\sqrt{3}$ & 0 & 0 \\
\hline
\end{tabular}


Table V Conjugacy Classes of the $S_{4}\left[S_{2}\right]$ group

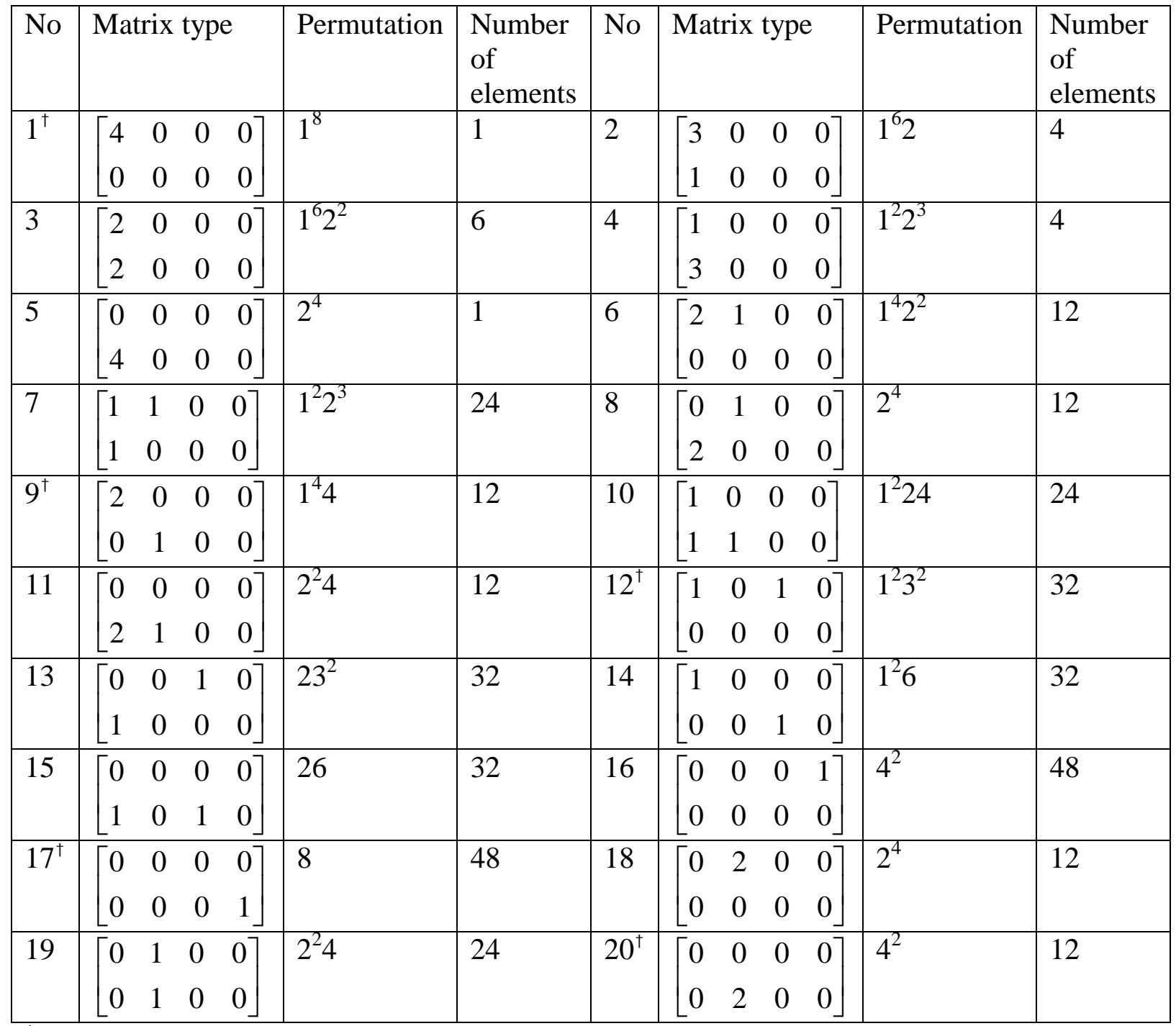

${ }^{\dagger}$ Classes that generate new classes in the double group. 
Table VI Irreducible Representations of the $S_{4}\left[S_{2}\right]$ group.

\begin{tabular}{|c|c|c|c|}
\hline Label & Irreducible Representation & Dimension & \\
\hline $\mathrm{A}_{1}$ & $([2] \#[2] \#[2] \#[2]) \otimes[4]^{\prime}$ & 1 & \\
\hline $\mathrm{T}_{1}$ & $([2] \#[2] \#[2] \#[2]) \otimes[31]^{\prime}$ & 3 & \\
\hline $\mathrm{E}_{1}$ & $([2] \#[2] \#[2] \#[2]) \otimes\left[2^{2}\right]^{\prime}$ & 2 & \\
\hline $\mathrm{T}_{2}$ & $([2] \#[2] \#[2] \#[2]) \otimes\left[21^{2}\right]^{\prime}$ & 3 & \\
\hline $\mathrm{A}_{2}$ & $([2] \#[2] \#[2] \#[2]) \otimes\left[1^{4}\right]^{\prime}$ & 1 & \\
\hline $\mathrm{G}_{1}$ & $\begin{array}{l}([2] \#[2] \#[2]) \otimes[3]^{\prime} \\
\#\left(\left[1^{2}\right] \otimes[1]^{\prime}\right.\end{array}$ & 4 & \\
\hline $\mathrm{K}_{1}$ & $\begin{array}{l}([2] \#[2] \#[2]) \otimes[21]^{\prime} \\
\#\left(\left[1^{2}\right] \otimes[1]^{\prime}\right.\end{array}$ & 8 & \\
\hline $\mathrm{G}_{2}$ & $\begin{array}{l}([2] \#[2] \#[2]) \otimes\left[1^{3}\right]^{\prime} \\
\#\left(\left[1^{2}\right] \otimes[1]^{\prime}\right.\end{array}$ & 4 & \\
\hline $\mathrm{I}_{1}$ & $\begin{array}{l}([2] \#[2]) \otimes[2]^{\prime} \\
\#\left(\left[1^{2}\right] \#\left(\left[1^{2}\right] \otimes[2]^{\prime}\right.\right.\end{array}$ & 6 & \\
\hline $\mathrm{I}_{2}$ & $\begin{array}{l}([2] \#[2]) \otimes[2]^{\prime} \\
\#\left(\left[1^{2}\right] \#\left(\left[1^{2}\right] \otimes\left[1^{2}\right]^{\prime}\right.\right.\end{array}$ & 6 & \\
\hline $\mathrm{I}_{3}$ & $\begin{array}{l}([2] \#[2]) \otimes\left[1^{2}\right]^{\prime} \\
\#\left(\left[1^{2}\right] \#\left(\left[1^{2}\right] \otimes[2]^{\prime}\right.\right.\end{array}$ & 6 & \\
\hline$\overline{\mathrm{I}_{4}}$ & $\begin{array}{l}([2] \#[2]) \otimes\left[1^{2}\right]^{\prime} \\
\#\left(\left[1^{2}\right] \#\left(\left[1^{2}\right] \otimes\left[1^{2}\right]^{\prime}\right.\right.\end{array}$ & 6 & \\
\hline $\mathrm{G}_{3}$ & $\begin{array}{l}\left(\left[1^{2}\right] \#\left[1^{2}\right] \#\left[1^{2}\right]\right) \otimes[3]^{\prime} \\
\#\left([2] \otimes[1]^{\prime}\right.\end{array}$ & 4 & \\
\hline $\mathrm{K}_{2}$ & $\begin{array}{l}\left(\left[1^{2}\right] \#\left[1^{2}\right] \#\left[1^{2}\right]\right) \otimes[21]^{\prime} \\
\#\left([2] \otimes[1]^{\prime}\right.\end{array}$ & 8 & \\
\hline $\mathrm{G}_{4}$ & $\begin{array}{l}\left(\left[1^{2}\right] \#\left[1^{2}\right] \#\left[1^{2}\right]\right) \otimes\left[1^{3}\right]^{\prime} \\
\#\left([2] \otimes[1]^{\prime}\right.\end{array}$ & 4 & \\
\hline $\mathrm{A}_{3}$ & $\left(\left[1^{2}\right] \#\left[1^{2}\right] \#\left[1^{2}\right] \#\left[1^{2}\right]\right) \otimes[4]^{\prime}$ & 1 & \\
\hline $\mathrm{T}_{3}$ & $\left(\left[1^{2}\right] \#\left[1^{2}\right] \#\left[1^{2}\right] \#\left[1^{2}\right]\right) \otimes[31]^{\prime}$ & 3 & \\
\hline $\mathrm{E}_{2}$ & $\left(\left[1^{2}\right] \#\left[1^{2}\right] \#\left[1^{2}\right] \#\left[1^{2}\right]\right) \otimes\left[2^{2}\right]^{\prime}$ & 2 & \\
\hline $\mathrm{T}_{4}$ & $\left(\left[1^{2}\right] \#\left[1^{2}\right] \#\left[1^{2}\right] \#\left[1^{2}\right]\right) \otimes\left[21^{2}\right]^{\prime}$ & 3 & \\
\hline $\mathrm{A}_{4}$ & $\left(\left[1^{2}\right] \#\left[1^{2}\right] \#\left[1^{2}\right] \#\left[1^{2}\right]\right) \otimes\left[1^{4}\right]^{\prime}$ & 1 & \\
\hline
\end{tabular}


Table VII Character Table of the $\left\{\mathrm{S}_{4}\left[\mathrm{~S}_{2}\right]\right\}^{2}$ double group with 25 irreducible reps

\begin{tabular}{|c|c|c|c|c|c|c|c|c|c|c|c|c|c|c|c|c|c|c|c|c|c|c|c|c|c|}
\hline & $1^{8}$ & $1^{6} 2$ & $1^{4} 2^{2}$ & $1^{2} 2^{3}$ & $2^{4}$ & $1^{4} 2^{2}$ & $1^{2} 22^{2}$ & $2^{4}$ & $1^{4} 4$ & $1^{2} 24$ & $2^{2} 4$ & $1^{2} 3^{2}$ & $23^{2}$ & $1^{2} 6$ & 26 & $4^{2}$ & 8 & $2^{4}$ & $2^{2} 4$ & $4^{2}$ & $\mathrm{R} 1^{8}$ & $\mathrm{R} 1^{4} 4$ & $\mathrm{R} 4^{2}$ & $\begin{array}{l}\mathrm{R} 1^{2} \\
3^{2}\end{array}$ & R8 \\
\hline & 1 & $\begin{array}{l}4 \\
{[8]}\end{array}$ & $\begin{array}{l}6 \\
{[12]}\end{array}$ & $\begin{array}{l}4 \\
{[8]}\end{array}$ & $\begin{array}{l}1 \\
{[2]}\end{array}$ & $\begin{array}{l}12 \\
{[24]}\end{array}$ & $\begin{array}{l}24 \\
{[48]}\end{array}$ & $\begin{array}{l}12 \\
{[24]}\end{array}$ & 12 & $\begin{array}{l}24 \\
{[48]}\end{array}$ & $\begin{array}{l}12 \\
{[24]}\end{array}$ & 32 & $\begin{array}{l}32 \\
{[64]}\end{array}$ & $\begin{array}{l}32 \\
{[64]}\end{array}$ & $\begin{array}{l}32 \\
{[64]}\end{array}$ & $\begin{array}{l}48 \\
{[96]}\end{array}$ & 48 & $\begin{array}{l}12 \\
{[24]}\end{array}$ & $\begin{array}{l}24 \\
{[48]}\end{array}$ & 12 & 1 & 12 & 12 & 32 & 48 \\
\hline $\mathrm{A}_{1}$ & 1 & 1 & 1 & 1 & 1 & 1 & 1 & 1 & 1 & 1 & 1 & 1 & 1 & 1 & 1 & 1 & 1 & 1 & 1 & 1 & 1 & 1 & 1 & 1 & 1 \\
\hline $\mathrm{A}_{2}$ & 1 & 1 & 1 & 1 & 1 & -1 & -1 & -1 & -1 & -1 & -1 & 1 & 1 & 1 & 1 & -1 & -1 & 1 & 1 & 1 & 1 & -1 & 1 & 1 & -1 \\
\hline $\mathrm{A}_{3}$ & 1 & -1 & 1 & -1 & 1 & 1 & -1 & 1 & -1 & 1 & -1 & 1 & -1 & -1 & 1 & 1 & -1 & 1 & -1 & 1 & 1 & -1 & 1 & 1 & -1 \\
\hline $\mathrm{A}_{4}$ & 1 & -1 & 1 & -1 & 1 & -1 & 1 & -1 & 1 & -1 & 1 & 1 & -1 & -1 & 1 & -1 & 1 & 1 & -1 & 1 & 1 & 1 & 1 & 1 & 1 \\
\hline$E_{1}$ & 2 & 2 & 2 & 2 & 2 & 0 & 0 & 0 & 0 & 0 & 0 & -1 & -1 & -1 & -1 & 0 & 0 & 2 & 2 & 2 & 2 & 0 & 2 & -1 & 0 \\
\hline$E_{2}$ & 2 & -2 & 2 & -2 & 2 & 0 & 0 & 0 & 0 & 0 & 0 & -1 & 1 & 1 & -1 & 0 & 0 & 2 & -2 & 2 & 2 & 0 & 2 & -1 & 0 \\
\hline $\mathrm{T}_{1}$ & 3 & 3 & 3 & 3 & 3 & 1 & 1 & 1 & 1 & 1 & 1 & 0 & 0 & 0 & 0 & -1 & -1 & -1 & -1 & -1 & 3 & 1 & -1 & 0 & -1 \\
\hline $\mathrm{T}_{2}$ & 3 & 3 & 3 & 3 & 3 & -1 & -1 & -1 & -1 & -1 & -1 & 0 & 0 & 0 & 0 & 1 & 1 & -1 & -1 & -1 & 3 & -1 & -1 & 0 & 1 \\
\hline $\mathrm{T}_{3}$ & 3 & -3 & 3 & -3 & 3 & 1 & -1 & 1 & -1 & 1 & -1 & 0 & 0 & 0 & 0 & -1 & 1 & -1 & 1 & -1 & 3 & -1 & -1 & 0 & 1 \\
\hline $\mathrm{T}_{4}$ & 3 & -3 & 3 & -3 & 3 & -1 & 1 & -1 & 1 & -1 & 1 & 0 & 0 & 0 & 0 & 1 & -1 & -1 & 1 & -1 & 3 & 1 & -1 & 0 & -1 \\
\hline $\mathrm{G}_{1}$ & 4 & 2 & 0 & -2 & -4 & 2 & 0 & -2 & 2 & 0 & -2 & 1 & -1 & 1 & -1 & 0 & 0 & 0 & 0 & 0 & 4 & 2 & 0 & 1 & 0 \\
\hline $\mathrm{G}_{2}$ & 4 & 2 & 0 & -2 & -4 & -2 & 0 & 2 & -2 & 0 & 2 & 1 & -1 & 1 & -1 & 0 & 0 & 0 & 0 & 0 & 4 & -2 & 0 & 1 & 0 \\
\hline $\mathrm{G}_{3}$ & 4 & -2 & 0 & 2 & -4 & 2 & 0 & -2 & -2 & 0 & 2 & 1 & 1 & -1 & -1 & 0 & 0 & 0 & 0 & 0 & 4 & -2 & 0 & 1 & 0 \\
\hline $\mathrm{G}_{4}$ & 4 & -2 & 0 & 2 & -4 & -2 & 0 & 2 & 2 & 0 & -2 & 1 & 1 & -1 & -1 & 0 & 0 & 0 & 0 & 0 & 4 & 2 & 0 & 1 & 0 \\
\hline $\mathrm{I}_{1}$ & 6 & 0 & -2 & 0 & 6 & 2 & 0 & 2 & 0 & -2 & 0 & 0 & 0 & 0 & 0 & 0 & 0 & 2 & 0 & -2 & 6 & 0 & -2 & 0 & 0 \\
\hline $\mathrm{I}_{2}$ & 6 & 0 & -2 & 0 & 6 & 0 & -2 & 0 & 2 & 0 & 2 & 0 & 0 & 0 & 0 & 0 & 0 & -2 & 0 & 2 & 6 & 0 & 2 & 0 & 0 \\
\hline $\mathrm{I}_{3}$ & 6 & 0 & -2 & 0 & 6 & 0 & 2 & 0 & -2 & 0 & -2 & 0 & 0 & 0 & 0 & 0 & 0 & -2 & 0 & 2 & 6 & 0 & 2 & 0 & 0 \\
\hline $\mathrm{I}_{4}$ & 6 & 0 & -2 & 0 & 6 & -2 & 0 & -2 & 0 & 2 & 0 & 0 & 0 & 0 & 0 & 0 & 0 & 2 & 0 & -2 & 6 & 0 & -2 & 0 & 0 \\
\hline $\mathrm{K}_{1}$ & 8 & 4 & 0 & -4 & -8 & 0 & 0 & 0 & 0 & 0 & 0 & -1 & 1 & -1 & 1 & 0 & 0 & 0 & 0 & 0 & 8 & 0 & 0 & -1 & 0 \\
\hline $\mathrm{K}_{2}$ & 8 & -4 & 0 & 4 & -8 & 0 & 0 & 0 & 0 & 0 & 0 & -1 & -1 & 1 & 1 & 0 & 0 & 0 & 0 & 0 & 8 & 0 & 0 & 1 & 0 \\
\hline$\underline{\mathrm{G}}_{1}$ & 4 & 0 & 0 & 0 & 0 & 0 & 0 & 0 & $-2 \sqrt{2}$ & 0 & 0 & 2 & 0 & 0 & 0 & 0 & $\sqrt{2}$ & 0 & 0 & 2 & -2 & $2 \sqrt{2}$ & -2 & -2 & $-\sqrt{2}$ \\
\hline$\underline{\mathrm{G}}_{2}$ & 4 & 0 & 0 & 0 & 0 & 0 & 0 & 0 & $2 \sqrt{2}$ & 0 & 0 & 2 & 0 & 0 & 0 & 0 & $-\sqrt{2}$ & 0 & 0 & 2 & -2 & $-2 \sqrt{2}$ & -2 & -2 & $-\sqrt{2}$ \\
\hline $\mathrm{K}$ & 8 & 0 & 0 & 0 & 0 & 0 & 0 & 0 & 0 & 0 & 0 & -2 & 0 & 0 & 0 & 0 & 0 & 0 & 0 & 4 & 8 & 0 & -4 & 2 & 0 \\
\hline$\underline{\mathrm{O}}_{1}$ & 12 & 0 & 0 & 0 & 0 & 0 & 0 & 0 & $-2 \sqrt{2}$ & 0 & 0 & 0 & 0 & 0 & 0 & 0 & $-\sqrt{2}$ & 0 & 0 & -2 & -12 & $2 \sqrt{2}$ & 2 & 0 & $\sqrt{2}$ \\
\hline $\mathrm{O} 2$ & 12 & 0 & 0 & 0 & 0 & 0 & 0 & 0 & $2 \sqrt{2}$ & 0 & 0 & 0 & 0 & 0 & 0 & 0 & $\sqrt{2}$ & 0 & 0 & -2 & -12 & $-2 \sqrt{2}$ & 2 & 0 & $-\sqrt{2}$ \\
\hline
\end{tabular}


Table VIII Non-rigid ${ }^{2} \mathrm{H}$ and ${ }^{3}$ Deuterium nuclear Spin Species of non-rigid $\left(\mathrm{PoH}_{2}\right)_{4}$ and $\left(\mathrm{PoD}_{2}\right)_{4}$.

\begin{tabular}{|c|c|c|}
\hline Symmetry & ${ }^{3}$ D Species & ${ }^{2}$ Proton Species \\
\hline$\overline{\mathrm{A}_{1}}$ & $\begin{array}{l}{ }^{1} \mathrm{~A}_{1}(4),{ }^{5} \mathrm{~A}_{1}(5), \\
{ }^{7} \mathrm{~A}_{1}(1),{ }^{9} \mathrm{~A}_{1}(4), \\
{ }^{11} \mathrm{~A}_{1}(1),{ }^{13} \mathrm{~A}_{1}(2) \\
{ }^{17} \mathrm{~A}_{1}(1)\end{array}$ & $\begin{array}{l}{ }^{1} \mathrm{~A}_{1}(1),{ }^{5} \mathrm{~A}_{1}(1) \\
{ }^{9} \mathrm{~A}_{1}(1)\end{array}$ \\
\hline $\mathrm{A}_{2}$ & $\begin{array}{l}{ }^{3} \mathrm{~A}_{2}(1){ }^{5} \mathrm{~A}_{2}(1) \\
{ }^{7} \mathrm{~A}_{2}(1)\end{array}$ & None \\
\hline $\mathrm{A}_{3}$ & $\begin{array}{l}{ }^{1} \mathrm{~A}_{3}(1){ }^{5} \mathrm{~A}_{3}(1) \\
{ }^{9} \mathrm{~A}_{3}(1)\end{array}$ & ${ }^{1} \mathrm{~A}_{3}(1)$ \\
\hline $\mathrm{A}_{4}$ & None & None \\
\hline$\overline{E_{1}}$ & $\begin{array}{l}{ }^{1} \mathrm{E}_{1}(3){ }^{3} \mathrm{E}_{1}(1) \\
{ }^{5} \mathrm{E}_{1}(5){ }^{7} \mathrm{E}_{1}(2) \\
{ }^{9} \mathrm{E}_{1}(4){ }^{11} \mathrm{E}_{1}(1) \\
{ }^{13} \mathrm{E}_{1}(1)\end{array}$ & ${ }^{1} \mathrm{E}_{1}(1),{ }^{5} \mathrm{E}_{1}(1)$ \\
\hline $\mathrm{E}_{2}$ & ${ }^{1} \mathrm{E}_{2}(1){ }^{5} \mathrm{E}_{2}(1)$ & None \\
\hline $\mathrm{T}_{1}$ & $\begin{array}{l}{ }^{1} \mathrm{~T}_{1}(2),{ }^{3} \mathrm{~T}_{1}(4) \\
{ }^{5} \mathrm{~T}_{1}(7),{ }^{7} \mathrm{~T}_{1}(6) \\
{ }^{9} \mathrm{~T}_{1}(5),{ }^{11} \mathrm{~T}_{1}(3) \\
{ }^{13} \mathrm{~T}_{1}(2),{ }^{15} \mathrm{~T}_{1}(1)\end{array}$ & $\begin{array}{l}{ }^{3} \mathrm{~T}_{1}(1),{ }^{5} \mathrm{~T}_{1}(1) \\
{ }^{7} \mathrm{~T}_{1}(1)\end{array}$ \\
\hline $\mathrm{T}_{2}$ & $\begin{array}{l}{ }^{3} \mathrm{~T}_{2}(5),{ }^{5} \mathrm{~T}_{2}(3) \\
{ }^{7} \mathrm{~T}_{2}(5),{ }^{9} \mathrm{~T}_{2}(2) \\
{ }^{11} \mathrm{~T}_{2}(2)\end{array}$ & ${ }^{3} \mathrm{~T}_{2}(1)$ \\
\hline $\mathrm{T}_{3}$ & $\begin{array}{l}{ }^{3} \mathrm{~T}_{3}(1),{ }^{5} \mathrm{~T}_{2}(1) \\
{ }^{7} \mathrm{~T}_{2}(1)\end{array}$ & None \\
\hline $\mathrm{T}_{4}$ & ${ }^{3} \mathrm{~T}_{4}(1)$ & None \\
\hline
\end{tabular}




\begin{tabular}{|c|c|c|}
\hline $\mathrm{G}_{1}$ & $\begin{array}{l}{ }^{3} \mathrm{G}_{1}(6),{ }^{5} \mathrm{G}_{1}(4) \\
{ }^{7} \mathrm{G}_{1}(6),{ }^{9} \mathrm{G}_{1}(3) \\
{ }^{11} \mathrm{G}_{1}(3),{ }^{13} \mathrm{G}_{1}(1) \\
{ }^{15} \mathrm{G}_{1}(1)\end{array}$ & ${ }^{3} \mathrm{G}_{1}(1),{ }^{7} \mathrm{G}_{1}(1)$ \\
\hline $\mathrm{G}_{2}$ & $\begin{array}{l}{ }^{1} \mathrm{G}_{2}(2),{ }^{3} \mathrm{G}_{2}(2), \\
{ }^{5} \mathrm{G}_{2}(4),{ }^{7} \mathrm{G}_{2}(2), \\
{ }^{9} \mathrm{G}_{2}(2)\end{array}$ & ${ }^{1} G_{2}(1)$ \\
\hline $\mathrm{G}_{3}$ & $\begin{array}{l}{ }^{3} \mathrm{G}_{3}(3),{ }^{5} \mathrm{G}_{2}(2) \\
{ }^{7} \mathrm{G}_{2}(3),{ }^{9} \mathrm{G}_{3}(1), \\
{ }^{11} \mathrm{G}_{3}(1)\end{array}$ & ${ }^{3} \mathrm{G}_{3}(1)$ \\
\hline $\mathrm{G}_{4}$ & ${ }^{1} \mathrm{G}_{4}(1),{ }^{5} \mathrm{G}_{4}(1)$ & None \\
\hline $\mathrm{I}_{1}$ & $\begin{array}{l}{ }^{1} \mathrm{I}_{1}(4),{ }^{3} \mathrm{I}_{1}(2), \\
{ }^{5} \mathrm{I}_{1}(7),{ }^{7} \mathrm{I}_{1}(3), \\
{ }^{9} \mathrm{I}_{1}(4),{ }^{11} \mathrm{I}_{1}(1) \\
{ }^{13} \mathrm{I}_{1}(1),{ }^{15} \mathrm{I}_{1}(1)\end{array}$ & ${ }^{1} \mathrm{I}_{1}(1),{ }^{5} \mathrm{I}_{1}(1)$ \\
\hline $\mathrm{I}_{2}$ & $\begin{array}{l}{ }^{3} \mathrm{I}_{2}(4),{ }^{5} \mathrm{I}_{2}(2), \\
{ }^{7} \mathrm{I}_{2}(3),{ }^{9} \mathrm{I}_{2}(1), \\
{ }^{11} \mathrm{I}_{2}(1)\end{array}$ & None \\
\hline $\mathrm{I}_{3}$ & $\begin{array}{l}{ }^{1} \mathrm{I}_{3}(1),{ }^{3} \mathrm{I}_{3}(4), \\
{ }^{5} \mathrm{I}_{2}(4),{ }^{7} \mathrm{I}_{3}(4), \\
{ }^{9} \mathrm{I}_{3}(2),{ }^{11} \mathrm{I}_{3}(1)\end{array}$ & ${ }^{3} I_{3}$ \\
\hline $\mathrm{I}_{4}$ & $\begin{array}{l}{ }^{1} \mathrm{I}_{4}(1),{ }^{3} \mathrm{I}_{3}(2), \\
{ }^{5} \mathrm{I}_{2}(3),{ }^{7} \mathrm{I}_{3}(2), \\
{ }^{9} \mathrm{I}_{3}(1),{ }^{11} \mathrm{I}_{3}(1)\end{array}$ & None \\
\hline $\mathrm{K}_{1}$ & $\begin{array}{l}{ }^{1} \mathrm{~K}_{1}(2),{ }^{3} \mathrm{~K}_{1}(7), \\
{ }^{5} \mathrm{~K}_{1}(8),{ }^{7} \mathrm{~K}_{1}(8), \\
{ }^{9} \mathrm{~K}_{1}(5),{ }^{11} \mathrm{~K}_{1}(3) \\
{ }^{13} \mathrm{~K}_{1}(1),\end{array}$ & ${ }^{3} \mathrm{~K}_{1}(1),{ }^{5} \mathrm{~K}_{1}(1)$ \\
\hline $\mathrm{K}_{2}$ & $\begin{array}{l}{ }^{1} \mathrm{~K}_{2}(1),{ }^{3} \mathrm{~K}_{2}(3), \\
{ }^{5} \mathrm{~K}_{2}(3),{ }^{7} \mathrm{~K}_{2}(2), \\
{ }^{9} \mathrm{~K}_{2}(1)\end{array}$ & None \\
\hline
\end{tabular}


Table IX Correlation Table for the rovibronic levels of $\mathrm{Tl}_{2} \mathrm{H}_{4}\left(\mathrm{Tl}_{2} \mathrm{H}_{4}{ }^{+}\right)$for both single and double valued representations.

\begin{tabular}{|c|c|c|}
\hline $\mathrm{K}$ & $\operatorname{Rigid}\left(\mathrm{D}_{2 \mathrm{~d}}^{2}\right)$ & Non-rigid( $\left.\left\{\mathrm{S}_{2}\left[\mathrm{~S}_{2}\right] \mathrm{XI}\right\}^{2}\right)$ \\
\hline 0 & $\mathrm{~A}_{1}$ & $\mathrm{~A}_{1}^{+}+\mathrm{A}_{1}^{-}$ \\
\hline 1 & $\mathrm{~A}_{2}+\mathrm{E}$ & $\mathrm{A}_{2}^{+}+\mathrm{A}_{2}^{-}+\mathrm{E}^{+}+\mathrm{E}^{-}$ \\
\hline 2 & $\mathrm{~A}_{1}+\mathrm{B}_{1}+\mathrm{B}_{2}+\mathrm{E}$ & $\begin{array}{l}\mathrm{A}_{1}^{+}+\mathrm{A}_{1}^{-}+\mathrm{B}_{1}^{+}+\mathrm{B}_{1}^{-} \\
+\mathrm{B}_{2}^{+}+\mathrm{B}_{2}^{-}+\mathrm{E}^{+}+\mathrm{E}^{-}\end{array}$ \\
\hline 3 & $\mathrm{~A}_{2}+\mathrm{B}_{1}+\mathrm{B}_{2}+2 \mathrm{E}$ & $\begin{array}{l}\mathrm{A}_{2}^{+}+\mathrm{A}_{2}^{-}+\mathrm{B}_{1}^{+}+\mathrm{B}_{1}^{-} \\
+\mathrm{B}_{2}^{+}+\mathrm{B}_{2}^{-}+2 \mathrm{E}^{+}+2 \mathrm{E}^{-}\end{array}$ \\
\hline 4 & $\left(\mathrm{~A}_{1}+\mathrm{A}_{2}+\mathrm{B}_{1}+\mathrm{B}_{2}+2 \mathrm{E}\right)+\mathrm{D}^{0}$ & $\begin{array}{l}\mathrm{A}_{1}^{+}+\mathrm{A}_{1}^{-}+\mathrm{A}_{2}^{+}+\mathrm{A}_{2}^{-} \\
+\mathrm{B}_{1}^{+}+\mathrm{B}_{1}^{-}+\mathrm{B}_{2}^{+}+\mathrm{B}_{2}^{-} \\
+2 \mathrm{E}^{+}+2 \mathrm{E}^{-}+\mathrm{D}^{0}\end{array}$ \\
\hline n(integer) & $\begin{array}{l}\left(\mathrm{A}_{1}+\mathrm{A}_{2}+\mathrm{B}_{1}+\mathrm{B}_{2}+2 \mathrm{E}\right) \\
+\mathrm{D}^{\mathrm{n}-4}\end{array}$ & $\begin{array}{l}\mathrm{A}_{1}^{+}+\mathrm{A}_{1}^{-}+\mathrm{A}_{2}^{+}+\mathrm{A}_{2}^{-} \\
+\mathrm{B}_{1}^{+}+\mathrm{B}_{1}^{-}+\mathrm{B}_{2}^{+}+\mathrm{B}_{2}^{-} \\
+2 \mathrm{E}^{+}+2 \mathrm{E}^{-}+\mathrm{D}^{\mathrm{n}-4}\end{array}$ \\
\hline $1 / 2$ & $\mathrm{E}_{1 / 2}$ & $\mathrm{E}_{1 / 2}^{+}+\mathrm{E}_{1 / 2}^{-}$ \\
\hline $3 / 2$ & $\mathrm{E}_{1 / 2}+\mathrm{E}_{3 / 2}$ & $\mathrm{E}_{1 / 2}^{+}+\mathrm{E}_{1 / 2}^{-}+\mathrm{E}_{3 / 2}{ }^{+}+\mathrm{E}_{3 / 2}{ }^{-}$ \\
\hline $5 / 2$ & $\mathrm{E}_{1 / 2}+2 \mathrm{E}_{3 / 2}$ & $\begin{array}{l}\mathrm{E}_{1 / 2}^{+}+\mathrm{E}_{1 / 2}^{-} \\
+2 \mathrm{E}_{3 / 2}^{+}+2 \mathrm{E}_{3 / 2}^{-}\end{array}$ \\
\hline $7 / 2$ & $2 \mathrm{E}_{1 / 2}+2 \mathrm{E}_{3 / 2}$ & $\begin{array}{l}2 \mathrm{E}_{1 / 2}^{+}+2 \mathrm{E}_{1 / 2}^{-} \\
+2 \mathrm{E}_{3 / 2}^{+}+2 \mathrm{E}_{3 / 2}^{-}\end{array}$ \\
\hline $9 / 2$ & $2\left(\mathrm{E}_{1 / 2}+\mathrm{E}_{3 / 2}\right)+\mathrm{D}^{(1 / 2)}$ & $\begin{array}{l}2\left(\mathrm{E}_{1 / 2}^{+}+\mathrm{E}_{1 / 2}+\mathrm{E}_{3 / 2}{ }^{+}+\mathrm{E}_{3 / 2}{ }^{-}\right) \\
+\mathrm{D}^{(1 / 2)}\end{array}$ \\
\hline $\mathrm{n}+1 / 2$ & $2\left(\mathrm{E}_{1 / 2}+\mathrm{E}_{3 / 2}\right)+\mathrm{D}^{(\mathrm{n}-1 / 2)}$ & $\begin{array}{l}2\left(\mathrm{E}_{1 / 2}^{+}+\mathrm{E}_{1 / 2}+\mathrm{E}_{3 / 2}{ }^{+}+\mathrm{E}_{3 / 2}{ }^{-}\right) \\
+\mathrm{D}^{(\mathrm{n}-1 / 2)}\end{array}$ \\
\hline
\end{tabular}

